\title{
Tres apuntes sobre la ciudad neoliberal en Costa Rica (1980-2017)
}

\author{
Ana Paula Montes Ruiz \\ Luis Durán Segura
}

Artículo

Invitados nacionales

Instituciones: Universidad Nacional Autónoma de México y Universidad de Costa Rica.

E-mail: Ana Paula Montes Ruiz: amontes@ comunidad.unam.mx

Luis Durán Segura: luarduse@yahoo.es

Recibido: 1 de setiembre de 2018

Aceptado: 6 de diciembre de 2018

\begin{abstract}
Ana Paula Montes Ruíz
Licenciada en Arquitectura (Universidad de Costa Rica), Master en Urbanismo (Universidad Politécnica de Cataluña, España), Doctoranda en Urbanismo (Universidad Autónoma Nacional de México). Filiación institucional: Universidad Autónoma Nacional de México - Becaria del Consejo Nacional de Ciencia y Tecnología de México.
\end{abstract}

\section{Luis Durán Segura}

Licenciado en Antropología (Universidad de Costa Rica), Magister en Antropología (Universidad de los Andes, Colombia), Magister en Estudios Culturales (Universidad de los Andes, Colombia), Doctorando en Estudios Latinoamericanos (Universidad Nacional, Costa Rica). Filiación institucional: Escuela de Arquitectura y Escuela de Geografía de la Universidad de Costa Rica.

\section{Resumen:}

El texto explora el contexto que, durante los últimos treinta y siete años, ha posibilitado la emergencia de la ciudad neoliberal en Costa Rica. Para ello, se realizan tres apuntes que muestran: i) los procesos de neoliberalización profunda provocados por el reescalamiento del Estado, la creación de programas aperturistas y la atracción de Inversión Extranjera Directa; ii) los procesos de reestructuración socioespacial de la Gran Área Metropolitana que inciden en la polarización del desarrollo de la ciudad en un eje este-oeste; y iii) los procesos de intensificación de la actividad inmobiliaria marcados por nuevas prácticas publicitarias alrededor de la vivienda.

Palabras Clave: ciudad neoliberal; contextualismo; Costa Rica; neoliberalización.

\section{Three notes on the neoliberal city in Costa Rica (1980-2017)}

\section{Abstract:}

The essay explores the emergence of the neoliberal city in Costa Rica within the sociopolitical context that has made it possible during the last thirty-seven years. In doing so, the text has been worked on three ideas: i) the processes of deep neoliberalization in which the State has not been weakening but instead rescaling to economic opening to attract direct foreign investment ii) the socio-spatial restructuring processes of the Great Metropolitan Area that affect the polarization of the development of the city on an east-west axis; and iii) the intensification processes of the urban real estate market.

Keywords: neoliberal city; contextualism; Costa Rica; neoliberalization. 
"La combinación de lo que es similar y de lo que es diferente define no sólo la especificidad histórica del momento, sino también de las preguntas que realizamos".

Stuart Hall

\section{Introducción}

I teórico cultural Stuart Hall recalcó, a lo largo de su obra, la importancia del análisis coyuntural como objeto y forma del trabajo intelectual, invitación que motiva la exploración de los objetos de estudio y del conjunto de articulaciones que los producen, sin reduccionismos y esencialismos. El autor, precisamente, consideró que un hecho 0 incluso una representación no existe independientemente de las fuerzas que le constituye, por lo que poseen, en su aparición, consolidación y transformación, una especificidad histórica (Hall, 1978). Esto en términos epistemológicos supone un llamado a abordar la realidad desde posturas radicalmente contextualistas.

Los contextos, entonces, no deben entenderse solo como escenarios donde se desarrollan las prácticas, sino como la misma posibilidad de las prácticas (Grossberg, 2009, p.29). Estos están forjados por entramados de articulaciones significantes, aunque no todas estas articulaciones sean idénticas 0 igualmente importantes para comprender las condiciones de emergencia de un acontecimiento 0 un evento (Restrepo, 2012, p. 133). Además, se tienen que pensar como relaciones contingentes y dinámicas (Grossberg, 2009, p. 30), ya que los contextos no están conformados por una única razón, sino por la unidad o condensación específica de múltiples vectores con diferentes espacialidades y temporalidades.

En este sentido, el texto explora el contexto que, durante los últimos treinta y siete años, ha posibilitado la emergencia de la ciudad neoliberal en Costa Rica. Así, a través de la ciudad neoliberal se estudia el proceso de ensamble de unas articulaciones, lucha de posiciones y juegos de estructuras, que ya no solo la recubren o envuelven, sino que también la hacen aparecer y afianzarse. Esta aproximación, particularmente, se enfoca en entender cómo ciertas transformaciones ocurridas tanto en las esferas económicas, políticas y sociales, se espacializan por medio de una singular urbanización neoliberal.

Los datos que acompañan el texto provienen de una revisión selectiva de fuentes secundarias. Por un lado, se recopilaron y sistematizaron informes y estadísticas que contenían referencias sobre los cambios ocurridos recientemente en la economía y en la política costarricense y, por el otro, trabajos académicos en formato de libros, tesis y artículos que analizaron temáticas urbanas que, si bien partían de otros intereses, sirvieron favorablemente para la argumentación dada. Por otro lado, los medios de comunicación, especialmente de la publicidad inmobiliaria, suministraron datos que estas dos fuentes anteriores no contemplaron. A partir de este corpus, se premió un enfoque construccionista para el análisis de la ciudad neoliberal en tanto situación histórico-geográfica concreta (Grossberg, 2009, p. 31).

El texto se organiza en tres apuntes y un cierre. El primer apunte se enfoca en el avance del proyecto neoliberal que, desde la década de 1980, ha propiciado una serie de acciones para incidir en el reescalamiento del Estado, en la creación de programas aperturistas y en la atracción de Inversión Extranjera Directa (IED). El segundo apunte se ocupa de las dinámicas de reestructuración socioespacial de la Gran Área Metropolitana que han implicado, en el presente siglo, el reemplazo de las antiguas centralidades por las actuales polaridades de desarrollo. El tercer apunte se encarga de mostrar la intensificación de la actividad inmobiliaria y los universos visuales que se asumen en las estrategias publicitarias alrededor del mercado de vivienda urbana luego de la crisis financiera del 2008. Por último, el cierre, realiza un balance de la discusión. 


\section{Apunte I. La neoliberalización profunda (1980-2000)}

Pensar la ciudad neoliberal en Costa Rica en una coyuntura de neoliberalización profunda, implica reconocer una serie acciones que han incidido en el reescalamiento del Estado, en la creación de programas aperturistas para la atracción de Inversión Extranjera Directa. A pesar de que Neil Brenner, Jamie Peck y Nik Theodore (2010) consideran una periodización por décadas para reconocer los distintos momentos de neoliberalización a escala global (una "neoliberalización desarticulada" en la década de 1970, una "transnacionalización de la neoliberalización" en la década de 1980 y una neoliberalización profunda a partir de la década de 1990), los investigadores de la historia contemporánea costarricense han utilizado otras periodizaciones y han señalado otro hitos para delimitar las particularidades del caso. Entre estos están:

El intervalo de tiempo en el que se pactaron los tres Programas de Ajuste Estructural (1985-1995).

El intervalo de tiempo que define la aplicación del Modelo de Ajuste Estructural (MAE- 1980-1999) y la entrada en vigor del Modelo de Libre Comercio (MOLC2000 - en adelante), considerando como hito el proyecto de ley para la apertura de las telecomunicaciones del año 2000.

El punto de inflexión provocado por el Modelo de Inversión Extranjera Directa a partir de la instalación, en 1998, de una sede de la corporación multinacional de microprocesadores Intel Corporation.

El punto de inflexión provocado por el Tratado de Libre Comercio entre República Dominicana, Centroamérica y Estados Unidos de América (CAFTA), desde que empezaron las negociaciones en el año 2003, hasta la entrada en vigor en Costa Rica a partir del año 2009.

No obstante, el proyecto de neoliberalización que aquí se discute quiere subrayar que, en el contexto costarricense, la neoliberalización es materialmente dependiente de un proceso de re-escalamiento del Estado, argumento por medio del que se explican las cambiantes matrices de la organización territorial del Estado y la incidencia de los nuevos marcos institucionales sub-nacionales en la producción y reconfiguración de las condiciones de producción específicas de lugar, para promover la competitividad estructural global de las ciudades y regiones principales (Brenner, 2003).

Según lo anterior, se entiende que, en su adaptabilidad, ya sea como Estadoempleador, Estado-empresario o Estado-financiero, ha conseguido institucionalizar el conflicto social y resolver las contradicciones que emergen a la luz del proyecto de neoliberación. En este sentido, la periodización responde a la necesidad de identificar: a) la transición de un Estado-empleador a un Estado-empresario en la década de 1970, b) la crisis de endeudamiento que justificó la implementación de los Programas de Ajuste Estructural en la década de 1980 y c) el proceso de pacificación que condujo a una neoliberalización a escala regional y a un Estado-financiero.

\section{Del estado-empleador al estado-empresario}

Aunque en la década de 1970 no se puede hablar del surgimiento de un proyecto neoliberal en Costa Rica, se aprecia el desplazamiento de un Estado centralista de corte gestor a un Estado de corte empresarial, antesala de la reforma neoliberal de la década siguiente. Este giro no puede comprenderse sin una serie de actores que aceptaron la ideología liberal durante la segunda mitad del siglo XX. Agenda que involucró a la sociedad civil (la clase media), la política de cooperación internacional que desplegó Estados Unidos a partir de 1961 (Cuerpos de Paz y el Programa Alianza para el Progreso de la Agencia Internacional para el Desarrollo USAID) y el proyecto político, económico y social que persiguió el bloque político-empresarial (Partido Liberación Nacional) después de la Guerra Civil de 1948.

Afalta de una industria pujante, el bloque político-empresarial al poder optó por incorporar y cooptar a los sectores medios dentro de los beneficios del esquema de reproducción social que orquestó el modelo de desarrollo a la "tica", entiéndase, la expansión del 
empleo a través del Estado y no a través de la pequeña propiedad (García, 2011, p. 298). En este sentido, y como han señalado varios investigadores, se trató de un proyecto transversal con:

Naturaleza "mesoclasista" (Delgado, 1983, p. 94) o "transclasista" (Quirós, 2007, p. 92) que consistió en una nivelación a largo plazo a través de una serie de reformas tecnocráticas (García, 2011, p. 279). Estas fueron viables en el marco del modelo de sustitución de importaciones y situaron a la inversión pública como el motor de desarrollo que intentó asegurar la convivencia de una sociedad igualitaria, pacífica y desconflictuada que incluiría a pequeños propietarios, comerciantes, intelectuales, empleados públicos, obreros y campesinos (Castro, 1995; Cordero, 2004; García, 2011).

Propiedades culturales ya que el Estado costarricense alcanzó grados elevados de legitimación por medio de la promoción de una oferta educativa, artística y mediática basada en los principios de la socialdemocracia (Cuevas, 1996). Como principal dinamizador de la vida pública, el Estado creó instituciones donde diferentes sectores hicieron parte de un ambiente hegemónico, compartiendo valores asociados a la homogeneidad racial (Contreras, 2013).

Carácter urbano por cuanto el acceso a la vivienda y a los servicios sociales (electricidad, telecomunicaciones, educación y salud) y, también, las nuevas instituciones, la inversión y el empleo orientado a dinamizar los circuitos secundarios y terciarios de acumulación de capital, tuvieron como escenario las principales ciudades del país (Alvarenga, 2005), coincidiendo, irónicamente, con un período caracterizado por la decadencia de la pequeña y mediana propiedad rural (García, 2011, p. 55).

Si bien a mediados de la década de 1980 la mayoría de los países de América Latina habían adoptado el modelo de sustitución de importaciones (Martí, 2000, p. 6), la crisis de este "desarrollo hacia adentro" y, por ende, la crisis del Estado-gestor, justificó la entrada del Estado-empresario. En Costa Rica este último, el Estado-empresario, en contraste con las funciones del Estado-empleador encargado de acaparar y distribuir las rentas y gestionar bienes y servicios públicos, se ocupó de defender el giro hacia el aperturismo bajo la denuncia de un Estado ineficiente y despilfarrador y de una clase media "parásita y acaparadora de la renta estatal" (Blanco, 2011 y García, 2011, p. 227).

El Estado-empresario representó un esfuerzo por relanzar el desarrollismo, ejecutando un proyecto de expansión económica con incidencia ya no en el ámbito urbano, sino en el regional mediante la creación de instituciones como la Academia de Centroamérica en 1969 y la Corporación Costarricense de Desarrollo (CODESA) en 1972. Funcionando bajo la figura de una sociedad anónima de capital mixto, con personería jurídica y patrimonio propio, CODESA operó como una "matriz de grandes empresas estatales" (Vega, 1984) y asumió la intermediación de empréstitos extranjeros que contribuyeron al crecimiento de la deuda externa en la década de 1970, lo que a la postre justificó la reforma neoliberal durante la década que siguió (Carvajal, 1993).

\section{La crisis de endeudamiento y los programas de ajuste estructural}

En el escenario de crisis macroeconómica de inicios de 1980, que tuvo entre sus múltiples orígenes el aumento del precio del petróleo y el aumento de las tasas de interés, los Programas de Ajuste Estructural (PAE) fueron implementados en Costa Rica de manera escalonada como respuesta directa ante las presiones del Fondo Monetario Internacional (FMI) y del Banco Mundial (BM). A lo largo de poco más de una década, los "préstamos blandos" (Carvajal, 1993) que hizo la USAID durante la administración de Luis Alberto Monge (1982-1986) y que sumaron alrededor de (USD) \$1.000 millones (Sojo, 1995; Flórez-Estrada, s.f.), constituyeron una profunda reforma del Estado y del modelo económico que había imperado hasta entonces.

EI PAE I (1985), PAE II (1989) y PAE III (1995) tuvieron el propósito de crear las condiciones para vincular la economía nacional con la economía mundial y asegurar el avance del capitalismo globalizado por medio de: 
La reducción del aparato estatal, la plantilla de empleados públicos y la privatización de empresas del sector público que habían sido creadas durante el período desarrollista (Acosta, 2006; Carvajal, 1993) bajo el discurso de la austeridad, la eficiencia y el máximo funcionamiento.

La modernización del sistema bancario y financiero nacional (Acosta, 2006; León, 2012) a partir de medidas que promovió el propio Banco Central de Costa Rica, como la liberalización de las tasas de interés en 1986 y la inyección de capital que hizo la USAID (Sojo, 1991, 1992; Flórez-Estrada, s.f.). Esto produjo, paralelamente, el nacimiento de la banca privada y la conformación de una élite financiera local (León, 2012; Flórez-Estrada, s.f.).

La liberalización de las transacciones comerciales para desarrollar las exportaciones con ayuda de la eliminación de impuestos aduaneros, la modificación de los controles de importación de productos agrícolas, la normativa de Régimen de Zonas Francas (Robles, 2010, 2011, 2012) y las subvenciones al sector turismo y agroindustrial (Carvajal, 1993).

La regionalización de grupos financieros, entre ellos Transportes Aéreos del Continente Americano (TACA), Grupo Roble, (ADOC), Garnier y Garnier, Durman Esquivel, Sardimar, Florida Ice \& Farm (Robles, 2010, 2011, 2012) y la transnacionalización de los capitales (Flórez- Estrada, s.f.).

La emergencia del "corporativismo" para la gestión privada de intereses públicos. Esto supuso la creación de un conjunto de entidades bajo la modalidad de asociaciones o fundaciones directamente vinculadas con el usufructo de recursos y presupuestos de instituciones estatales (Blanco, 2004, 2010, 2010a, 2010b) entre las que se encuentran la empresa Consultores Económicos y Financieros Sociedad Anónima (CEFSA) en 1978, el Instituto Nacional de Biodiversidad (INBio) en 1980, la Coalición de Iniciativas de Desarrollo (CINDE) en 1983, el Banco Nacional Hipotecario de la Vivienda (BANHVI) en 1986, la Fundación Omar Dengo en 1987 o la Fundación Arias para la Paz y el Progreso Humano en 1988.

\section{La pacificación y la neoliberalización a escala regional}

Durante la alineación de la región centroamericana con las políticas de reforma neoliberales, jugó un papel determinante la introducción del discurso pacifista, el cese del conflicto armado, la normalización política que supuso la firma de los Acuerdos de Paz y las elecciones democráticas que se sucedieron a lo largo de la década de 1990. Un proceso de pacificación que, como han señalado varios autores (Chomsky, 2001; Acosta, 2006; Berger, 1997, 2006), no puede comprenderse al margen de un giro gerencial y pragmático en la política exterior de Estados Unidos hacia la región, persiguiendo por medio de una intervención de tipo financiera, pasar de un proyecto de desarrollo nacional a un proyecto de globalización.

El abandono del enfoque "desarrollista" y la adopción de un enfoque "aperturista" estableció otro tipo de relaciones comerciales, ya no en función de la cooperación para la integración de los aparatos productivos centroamericanos sino, más bien, en función de la transnacionalización de las economías nacionales y de la incorporación de estas economías a los circuitos globales de producción y distribución (Robinson, 1998, p. 469). La apuesta implicó: i) la modernización, internacionalización y ascenso al poder de los principales grupos económicos nacionales; ii) la ampliación de una red tentacular de reformas a los marcos regulatorios y los sistemas legales a escala nacional, iii) aplicación de acuerdos institucionales a escala internacional como el CAFTA que culminó con el proceso de formalización institucional de la estrategia neoliberal y iv) la consolidación fragmentada y dependiente de la integración de las economías centroamericanas al mercado global (Saldomando, 2006, p. 6).

En el contexto costarricense, la transnacionalización fue posibilitada por la emergencia del Estado-financiero que ha implementado una serie de medidas como la Ley Reguladora de Mercado de Valores en 1990, la Ley 7210 de Zonas Francas en 1990, el ingreso de Costa Rica en la Organización Mundial de Comercio (OMC) en 1990 y la ejecución de la Reforma a la Ley Orgánica del Banco Central de Costa Rica en 
1995. Estas medidas tenían como objetivo promover ventajas competitivas territoriales, asegurar la atracción de Inversión Extranjera Directa y fomentar la instalación en el país de empresas multinacionales como es el caso de Intel Corporation en 1997, Procter \& Gamble en 1998 y tres megabancos privados (Banco BAC San José, Scotiabank y Banco HSBC) (León, 2012, p. 228-229).

Durante la década de 1990, las políticas para el desarrollo de las ventajas competitivas territoriales justificaron las modificaciones de la normativa vigente, los incentivos fiscales a las Empresas Transnacionales (ETN), la flexibilización de las condiciones de contratación de la fuerza de trabajo (Martínez, 2011) y, también, la creación de agencias gubernamentales que operan bajo las alianzas público-privadas. Por ejemplo, la Promotora de Comercio Exterior de Costa Rica (PROCOMER) en 1996 y el Fondo de Desarrollo Tecnológico (FODETEC) en 1990 mediante fondos del Banco Interamericano de Desarrollo (BID), quien otorgó créditos dirigidos al desarrollo tecnológico e innovación en Costa Rica.

Este primer apunte muestra que, a lo largo de treinta años, se asiste a la aparición de distintas reformas para liberar y privatizar servicios públicos, desregularizar la actividad financiera y crear entidades mixtas. En el último recorrido de este proceso, el escenario actual, se ha apostado por el Modelo de Inversión Extranjera Directa, política económica sobre la cual se han consolidado paulatinamente nuevos ejes de acumulación alrededor de empresas transnacionales del ámbito de las telecomunicaciones, del diseño y la exportación de software y de los bienes raíces.

Apunte II. Las dinámicas de reestructuración socio-espacial (20002017)

Pensar la ciudad neoliberal en Costa Rica supone discutir la actual transformación socioespacial de ciertas zonas de la Gran Área Metropolitana en el marco del proceso de re-escalamiento del Estado, explicado en el apartado anterior. Además, supone discutir un re-escalamiento de la urbanización que refuerza los patrones de segregación. El reescalamiento de la urbanización está orientada por las fuerzas del mercado y, no sólo se expresa en una distribución desigual de los grupos sociales, sino que se inscribe en el espacio a través de nuevas formaciones urbanas que producen archipiélagos aislados y discontinuos, y fronteras físicas y simbólicas.

Dentro de las dinámicas de reestructuración socio-espacial comprendidas entre el 2000 y el 2017, se observa un desarrollo polarizado en la Gran Área Metropolitana a lo largo de un eje este-oeste en el que emergen nuevas formaciones espaciales como los enclaves residenciales, comerciales y corporativos (las "gated communities", los "malls" y los "corporate centers"). Este nuevo modelo de urbanización está vinculado a los nuevos ejes de acumulación alrededor de empresas transnacionales del ámbito de las telecomunicaciones, del diseño y la exportación de software y de los bienes raíces, y se distingue de la forma urbana centralizada que emergió producto del Estado-empleador que concentró los servicios, las instituciones públicas y el empleo.

\section{Balance centroamericano}

La transformación socioespacial del Gran Área Metropolitana de Costa Rica durante los últimos 17 años trasciende la escala nacional y se instala en toda la región Centroamericana, lo cual implica la observación del fenómeno urbano más allá de las fronteras nacionales, considerando por ejemplo que el propio negocio inmobiliario también empieza a operar a una escala amplificada por medio de la regionalización de la banca, de las firmas de arquitectura, de las empresas inmobiliarias (Grupo Roble) y de las desarrolladoras así como también la instalación de franquicias de retail (Indetex, Starbucks, entre otras).

La reestructuración neoliberal en Centroamérica, como se ha mencionado, relevó el modelo de financiamiento estatal en favor de la incursión de una gestión urbana de corte empresarial (Lungo, 2005; Segovia, 2005; Rojas, 2010) en un escenario en donde el 
Estado ha tenido un papel históricamente debilitado en materia de planificación urbana, no solo por las limitaciones económicas, sino además por los conflictos políticos y bélicos de larga duración (Lungo \& Polèse, 1998).

La privatización de las empresas públicas, que erradicaron todo carácter regulador y centralizado de la planificación territorial y las inversiones de capital en la creación de infraestructura, se presentaron como únicas alternativas frente a los recortes en el financiamiento gubernamental en materia urbana (Abramo, 2012). En esta coyuntura, el mercado inmobiliario y los grupos de poder económico asociados, especialmente las élites empresariales centroamericanas, han devenido en actores significativos para la producción del espacio urbano en el Istmo.

La desigual distribución de la riqueza queda evidenciada en las contradicciones bajo las que opera actualmente la ciudad centroamericana, orientada desde las lógicas de un mercado inmobiliario segmentado que se ocupa tanto del mercado formal del suelo (para las clases medias y altas) (Polèse \& Lungo, 1998) como del mercado informal del suelo (para las clases bajas) (Abramo, 2003a, 2003b). Por lo tanto, se puede afirmar que articula una vulnerabilidad selectiva (Harvey, 2003), una polarización entre abundancia y miseria (Smith, 2001) y una violenta reordenación espacial de las relaciones de género, clase y raza (Smith, 2005).

Razón por la cual la urbanización neoliberal ha implicado un crecimiento fragmentado, acentuando una configuración segregativa que está relacionada con nuevos patrones de exclusividad. Las localidades aledañas a la carretera a Masaya en el Sur de Managua (Villa Fontana Sur, Notre Dame y Parque del Club), a lo largo de la carretera Panamericana y al Suroeste del Área Metropolitana de San Salvador (antigua finca El Espino y cantón El Carmen), al Sureste de la Área Metropolitana de Ciudad de Guatemala (Zona 10, Zona 15 y Zona 16) y en las periferias de Tegucigalpa (Colonias de San Ignacio, El Sauce, Las Hadas y Lomas de Guijarro), son ejemplos de cómo algunos grupos privilegiados se aíslan y concentran en determinadas zonas privilegias.

Sin embargo, este modelo avanza no solo posibilitando el proceso de urbanización fuera de los centros urbanos históricos de las ciudades centroamericanas, sino, además, participando de estrategias de recuperación de centros urbanos tradicionales que, como en Tegucigalpa, son amparadas en discursos de sistemas de paz y de seguridad (UMPEG, 2015). Asimismo, en la construcción de barrios cerrados y fortificados de San Salvador (Séguin \& Negrón, 2006) y en la política de reconstrucción de vivienda en Managua (Inzulza \& López, 2014). Los procesos de gentrificación y turistificación de ciudades coloniales como en el caso Granada (Foulds, 2014) o de Antigua Guatemala (Ferman, 2004; Becklake, 2014), también responden a este modelo.

Estas dinámicas muestran que la ciudad se convirtió en una pieza decisiva para las reformas neoliberales, destacando en este contexto dos casos significativos. Por una parte, Paseo Cayalá, situado en las afueras de Ciudad de Guatemala, proyecto desarrollado por Cayalá Management Group y diseñado en 2003 por el urbanista luxemburgués Leon Krier(The Guardian, 2013). Esta miniciudad, que posee edificaciones neocoloniales y neoclásicas, fue ideada para el disfrute de las élites guatemaltecas tanto como resguardo ante la creciente inseguridad como sitio de consumo y ocio. Paseo Cayalá materializa una de las nuevas fronteras de segregación, asegurando un aislamiento de los grupos de mayor riqueza a la vez que reduce los ámbitos de interacción de estos con el resto de la ciudad.

Por otra parte, el proyecto de las Zonas de Empleo y Desarrollo Económico (ZEDE), promovidas por el gobierno hondureño desde el 2013, encarna los procedimientos de Inversión Extranjera Directa (Wallace, 2017). La Zona de Empleo y Desarrollo Económico de Tegucigalpa particularmente muestran que el Estado, en el proceso de reestructuración escalar, perdió injerencia directa sobre la administración de la ciudad. Esta iniciativa ejemplifica las nuevas formas de polarización social, una agudización de las desigualdades en el territorio y las diferentes crisis de la gobernanza. Tegucigalpa, en este modelo, conforma un espacio gobernado por sectores empresariales que buscan la creación de centros financieros y logísticos internacionales, esferas autónomas de trabajo y distritos especiales de inversión, todos sujetas a sistemas jurídicos especiales. 


\section{Nueva polaridad este-oeste en la gran área metropolitana}

La Gran Área Metropolitana de Costa Rica, desde finales del siglo XX, sufrió una serie de transformaciones que, en términos generales, colocaron a las empresas privadas como actores principales de la economía urbana (Fürst, 2000a, 2000b). Esto, a la postre, tuvo implicaciones en la redistribución y ocupación del territorio (pérdida simbólica de un centro urbano por el crecimiento del eje este-este), pero, sobre todo, generó nuevas demandas, mercados y actividades lucrativas para un sector económico específico y restringido, concentrando la riqueza en localizaciones puntuales y para unos sectores restringidos de la población como lo muestra la Figura 1.

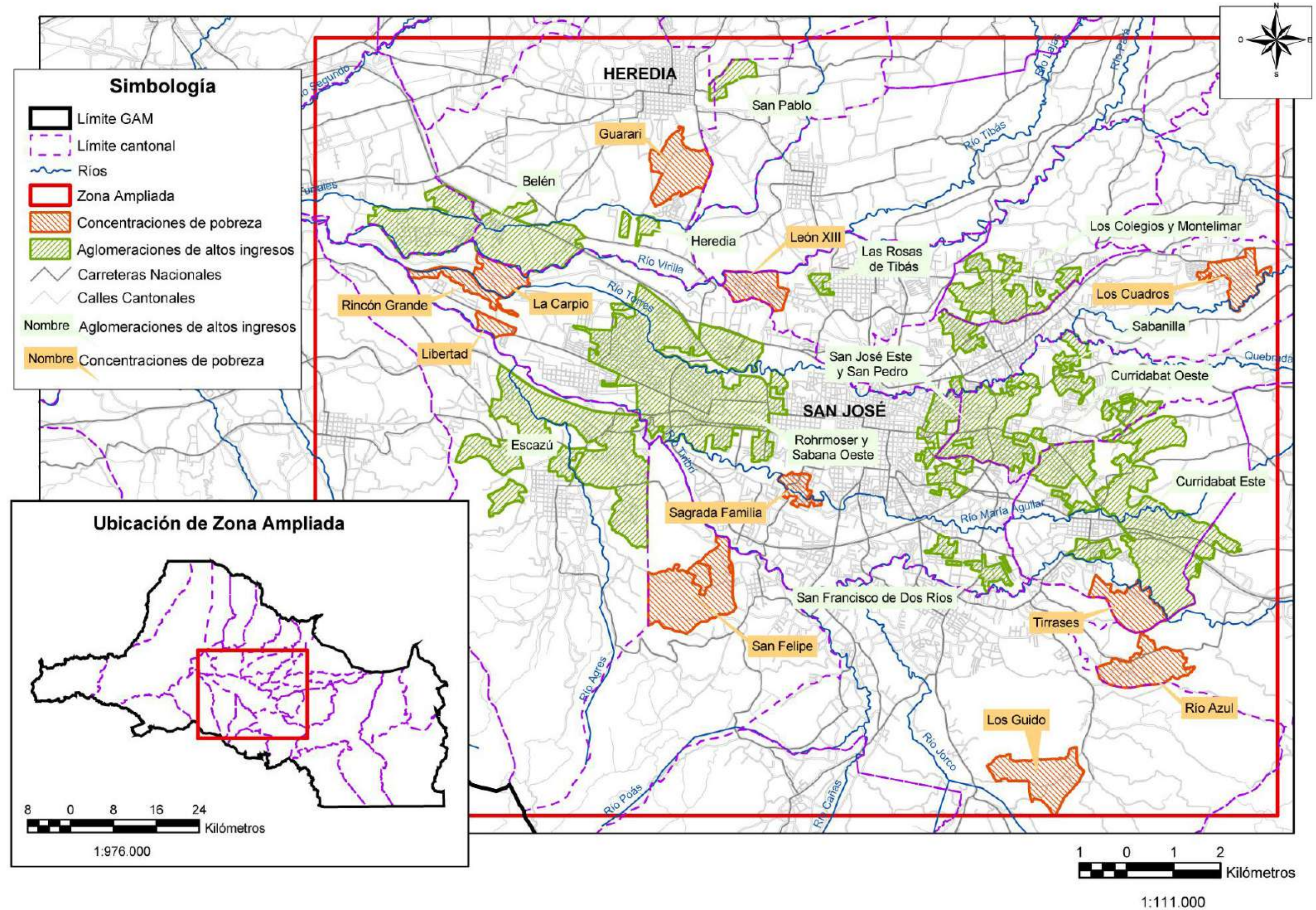

Figura 1. Mapa de aglomeraciones de altos y bajos ingresos en la Gran Área Metropolitana Fuente: PRUGAM (2004).
Entre los cambios acaecidos durante las primeras décadas del siglo XXI, resalta la emergencia de nuevas formaciones urbanas que establecen otro tipo de relación con el territorio a partir de una suerte de conexión-desconexión. La aparición de urbanizaciones cerradas, centros comerciales y centros corporativos, precisamente, se comprenden como fenómenos asociados a la liberalización del suelo, al fortalecimiento de actores inmobiliarios y al repliegue del Estado en materia de planificación urbana. El principal efecto ha sido una desconcentración urbana (desconexión con los centros tradicionales) y un crecimiento polarizado (conexión entre las zonas de la periferia).

Dentro de esas nuevas formaciones urbanas sobresalen los condominios 0 urbanizaciones cerradas que, imitando el modelo suburbano norteamericano (Thuillier, 2005), se caracterizan por una homogeneización social y de un estilo de vida basado en una organización privada y eficiente del vecindario, que provee de los servicios que antes eran públicos (Alvarado \& Jiménez, 2013). Esta solución residencial es predominante hoy entre los sectores de clase media-alta y alta en Costa Rica e implica, por un lado, el abandono de la política de vivienda estatal y, por otro, la delegación de la responsabilidad a los actores privados (Alvarado, 2016). 
Sumado a la emergencia de las urbanizaciones cerradas, aparecen los centros y plazas comerciales que aportan nuevas condiciones territoriales que transforman las dinámicas de consumo (Jiménez, 2017). Los centros comerciales, ubicados fuera de los centros urbanos tradicionales, devienen nodos de atracción comercial y residencial, al ofrecer arquitecturas compactas, estrictamente vigiladas y con sendas peatonales libres de la contaminación y de los riesgos del tráfico vehicular, dinámica homóloga a la aparición de los centros corporativos, comunes en el eje este-oeste, que permiten a los inversores ambientes protegidos con facilidades fiscales.

La presencia de centros comerciales confirma la popularidad de las nuevas macro superficies comerciales y corporativas de negocios que paulatinamente mutan en "life style centers", que se abren públicamente (Boza, Chávez \& Segura, 2015), con características de centros urbanos tradicionales (Gillem, 2009). En Avenida Escazú, caso paradigmático construido en 2009 sobre la autopista Próspero Fernández, se despliega un esfuerzo paisajístico para reforzar una idea de que el centro comercial tiene la capacidad de ofrecer vivienda, comercio, socialización, entretenimiento, salud, educación y trabajo. Un estilo de vida que apela al slogan "wellness lifestyle" o al "live, work and play".

\section{Nuevas concentraciones}

Según el Programa de Estado de la Nación, existe una acumulación desigual que se evidencia en el emplazamiento de la población de altos ingresos en sectores muy específicos de la Gran Área Metropolitana. En el mencionado eje este-oeste:

Se concentra la población con más recursos económicos en el distrito de Mata Redonda del cantón de San José (Sabana y Rohrmoser) y en los cantones de Escazú, Santa Ana y Belén. También, en los distritos de San Pedro y Sabanilla en el cantón de Montes de Oca, en el distrito de San Vicente en el cantón de Moravia y en los cantones de Curridabat y La Unión (PEN, 2004).

Se relocalizan las fuentes de empleo, por cuanto la concentración de empresas también se ha consolidado al oeste en las localidades de San Antonio en el cantón de Belén, de El Coyol en el cantón de Alajuela y al Este en la localidad de Coris en el Cantón de Cartago (PEN, 2015, p. 284-302).

- Se aglutinan las residencias de mayor tamaño promedio, con 186 m2, que es 2,8 veces la media nacional, 1,9 veces el promedio de la Gran Área Metropolitana, se localizan en los cantones de Escazú, Belén y Santa Ana y en el distrito de La Garita del cantón de Alajuela. Asimismo, en el distrito Sánchez del cantón de Curridabat y en los cantones de Montes de Oca y La Unión (PEN, 2015, p. 303).

Además, la oferta de vivienda nueva, como lo muestra la Figura 2, se está dando con mayor ímpetu en los cantones de Santa Ana, Escazú, Montes de Oca y Curridabat, en los distritos del sur del cantón de Alajuela y en los cantones de San Pablo y en el distrito Ulloa del cantón de Heredia. Debido a que el $90 \%$ de los proyectos y el $85 \%$ de las soluciones de vivienda de la oferta tienen montos por solución por encima de los (USD) $\$ 100.000$ para poder acceder a un crédito de ese monto, se requiere de ingresos mensuales de más de (USD) $\$ 3.500$, monto que, de acuerdo con la Encuesta Nacional de Hogares (ENAHO) del 2012, sólo lo percibe un 11,3\% de los hogares del país, por lo que se trata de una oferta centrada en una población o mercado sumamente restringido (Solano \& Rojas, 2013, p. 94).

En la construcción de apartamentos y condominios, como lo muestra la Figura 3, se observa una tendencia en los distritos de Mata Redonda, Merced, Hospital y Carmen que pertenecen al cantón de San José y en los cantones de Escazú, Tibás, Curridabat, Montes de Oca, Heredia, Belén y en el distrito central de Alajuela (Solano \& Rojas, 2013, p. 75).

Por lo anterior, se puede señalar una concentración excluyente en sentido este-oeste, que se da tanto por ingresos económicos como por acceso a centros de trabajo y entretenimiento que demanda la población de ingresos medios y medios altos. Esta tendencia no puede comprenderse fuera del proceso de terciarización de la economía 
que ha implicado la concentración de parques tecnológicos, oficentros, centros corporativos y comerciales que, a manera de islas, operan globalmente entre sus homólogas, mientras permanecen como espacios desarticulados del resto del territorio.

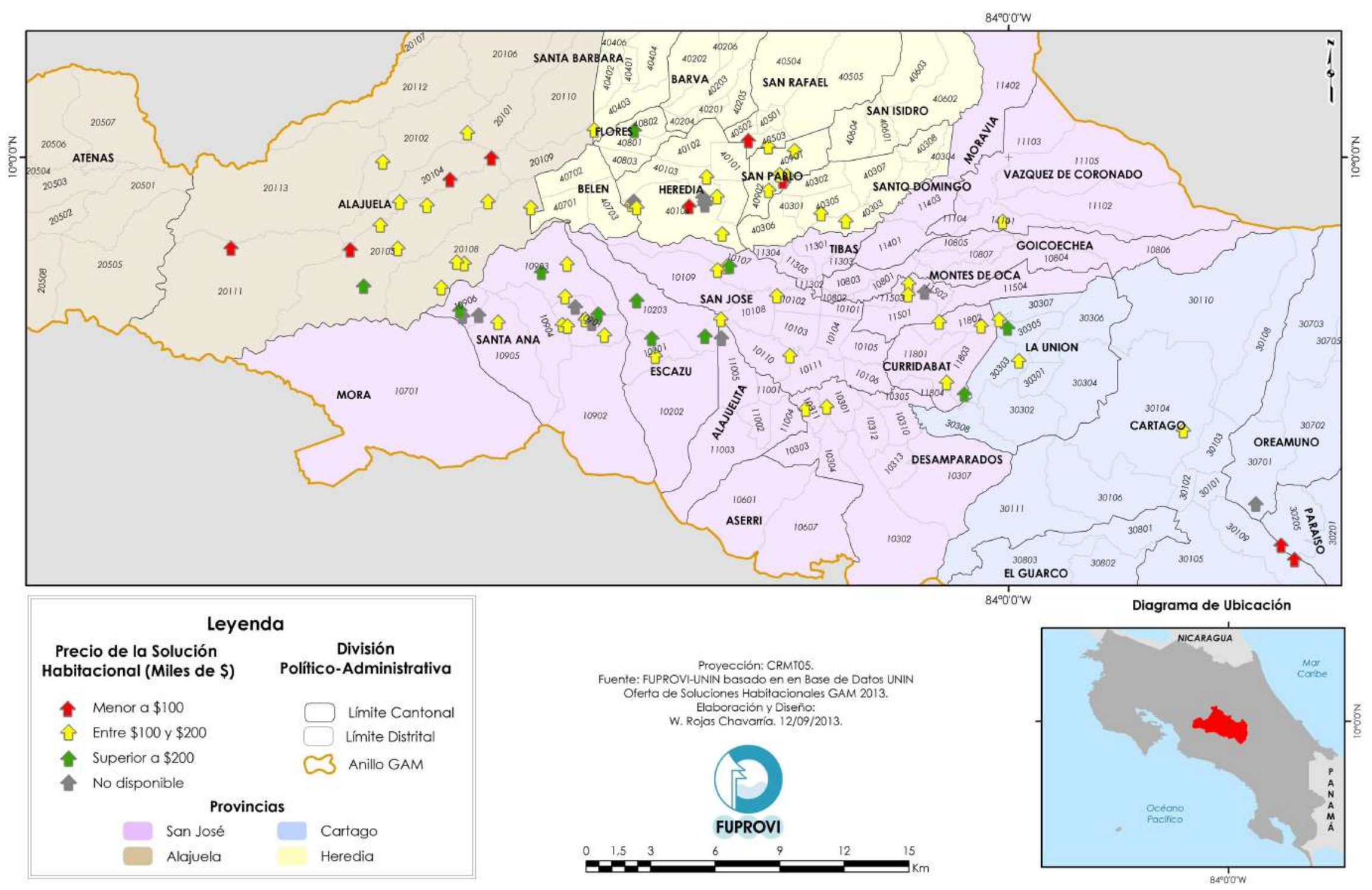

Figura 2. Mapa. Precio aproximado de la solución habitacional en la Gran Área Metropolitana. Fuente: Fundación Promotora de Vivienda (2012). A Figura 3. Mapa. Porcentaje de permisos de apartamentos y condominios, 2000-2012. Fuente: Fundación Promotora de Vivienda (2012). V

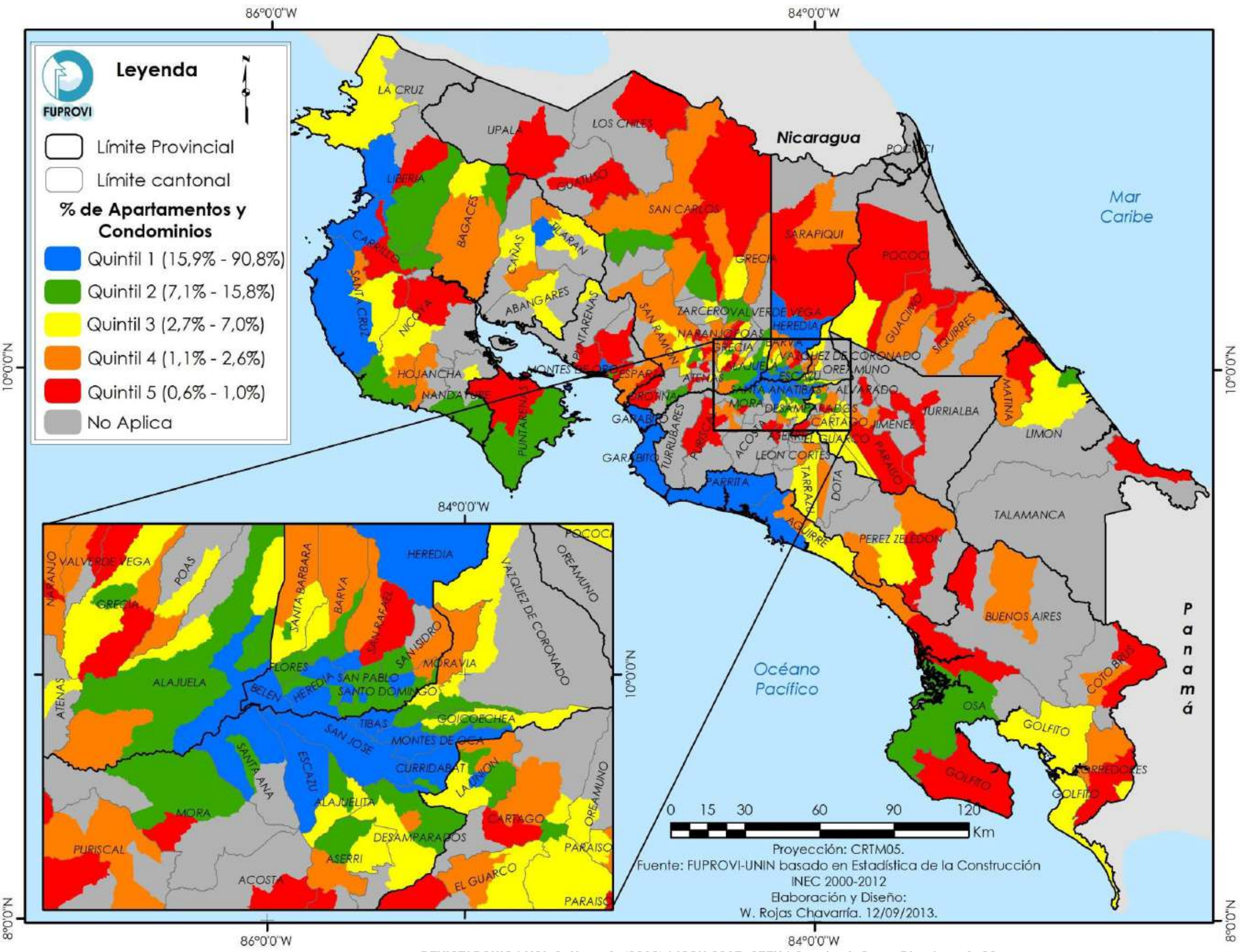


Esto ha generado una serie de archipiélagos en el interior urbano: "islas de riqueza", "islas de consumo", "islas de producción" e "islas de precariedad" (Janoschka, 2002). Resultado tanto del asentamiento insular de estructuras y funciones como también del aislamiento de espacios residenciales, laborales y recreativos mediante la construcción de muros. Este desarrollo de fragmentos urbanos, no integrados entre sí, entonces, es una de las principales características del desarrollo polarizado en la Gran Área Metropolitana.

\section{Apunte III. La intensificación de la actividad inmobiliaria urbana (2006-2017)}

Pensar la ciudad neoliberal en Costa Rica, en una coyuntura de intensificación de la actividad de los mercados inmobiliarios para el segmento urbano, significa identificar unas condiciones específicas de crecimiento (densificación y verticalización), uso del suelo (habitacional y mixto), tipología de edificación (torres y conjuntos en altura) y tenencia de la propiedad (condominio); e implica, sin duda, colocar la emergencia de la ciudad neoliberal dentro de una serie de problemáticas urbanas como el acceso a la vivienda, los mecanismos de financiamiento, las dinámicas demográficas $y$, especialmente, las prácticas publicitarias alrededor de la vivienda después de la crisis financiera del 2008.

Se constata en la publicidad inmobiliaria, inicialmente, un despliegue inusual de imágenes que responden a proyectos de vivienda en vertical y desarrollados por el sector privado para un segmento de ingresos medio-alto. Cuando esta información se contrasta con el hecho de que el Estado ha visto reducido sistemáticamente su rol como proveedor de vivienda social (Pujol et al., 2009, p.32), al punto de que la relación entre la cantidad de viviendas construidas por el sector privado versus sector público pasó de una relación de 1:1, a finales de la década de 1980, a una relación de 8:1 durante la última década (Pujol et al., 2009); por tanto, se infiere que: a) el sector privado se ha convertido en el principal proveedor de vivienda y b) el crecimiento de la ciudad tiende a la densificación y a la verticalización diferenciada para sectores de mayores ingresos, lo cual no quiere decir que el Estado haya dejado de participar en la activación del mercado de vivienda de financiamiento privado.

\section{De la costa a la ciudad}

Considerando una revisión de la publicidad inmobiliaria publicada a lo largo de diez años en la Revista Summa (principal grupo editorial de revistas en Centroamérica para el sector de negocios) y la localización georeferenciada de los proyectos publicitados, se observa en la Figura 4 que, hasta el año 2008, operó con fuerza en Costa Rica un mercado inmobiliario fundamentalmente de segundas residencias o de alojamiento turístico alimentado por el fenómeno de la movilidad migratoria que Michael Janoschka (2009) ha denominado como "lifestyle mobility". Y como se expone en Figura 5, la publicidad de proyectos inmobiliarios ubicados en el litoral Pacífico Norte y Central muestran el uso exclusivo del idioma inglés, referencias al lujo, la privacidad y la conveniencia de la proximidad a la línea de playa, denotando que el público meta al que se dirigían dichos desarrollos inmobiliarios eran, fundamentalmente, turistas extranjeros o jubilados norteamericanos (Puga, 2001).

Por el contrario, la misma Figura 4 muestra que la publicidad a partir del año 2013 responde a proyectos inmobiliarios localizados en la Gran Área Metropolitana y, en este sentido, evidencia la intensificación de la actividad de un mercado inmobiliario urbano cuyo objetivo claramente apunta a otro segmento poblacional. En este caso, la Figura 6 ejemplifica una estrategia publicitaria enfocada en un público de familias jóvenes de profesionales y por ello se destacan las ventajas que supone la vida urbana en condominios: exclusividad y privacidad sin aislamiento. Es decir, se subrayan las ventajas que ofrece la ciudad en materia de accesibilidad por medio de desplazamientos, que posibilitan disponer de tiempo libre para disfrutar del entretenimiento que ofrecen los mismos proyectos. 
Figura 4. Cantidad de anuncios publicitarios por ubicación del proyecto según año de publicación. Fuente: Realización propia con datos de publicidad inmobiliaria obtenida en consulta de 10 años de la Revista Summa.

Figura 5. Imágenes publicitarias de proyectos inmobiliarios ubicados en el litoral Pacífico de Costa Rica. Fuente: Realización propia con datos de publicidad inmobiliaria obtenida en consulta de 10 años de la Revista Summa.

Figura 6. Imágenes publicitarias de proyectos inmobiliarios ubicados en la Gran Área Metropolitana. Fuente: Realización propia con datos de publicidad inmobiliaria obtenida en consulta de 10 años de la Revista Summa.
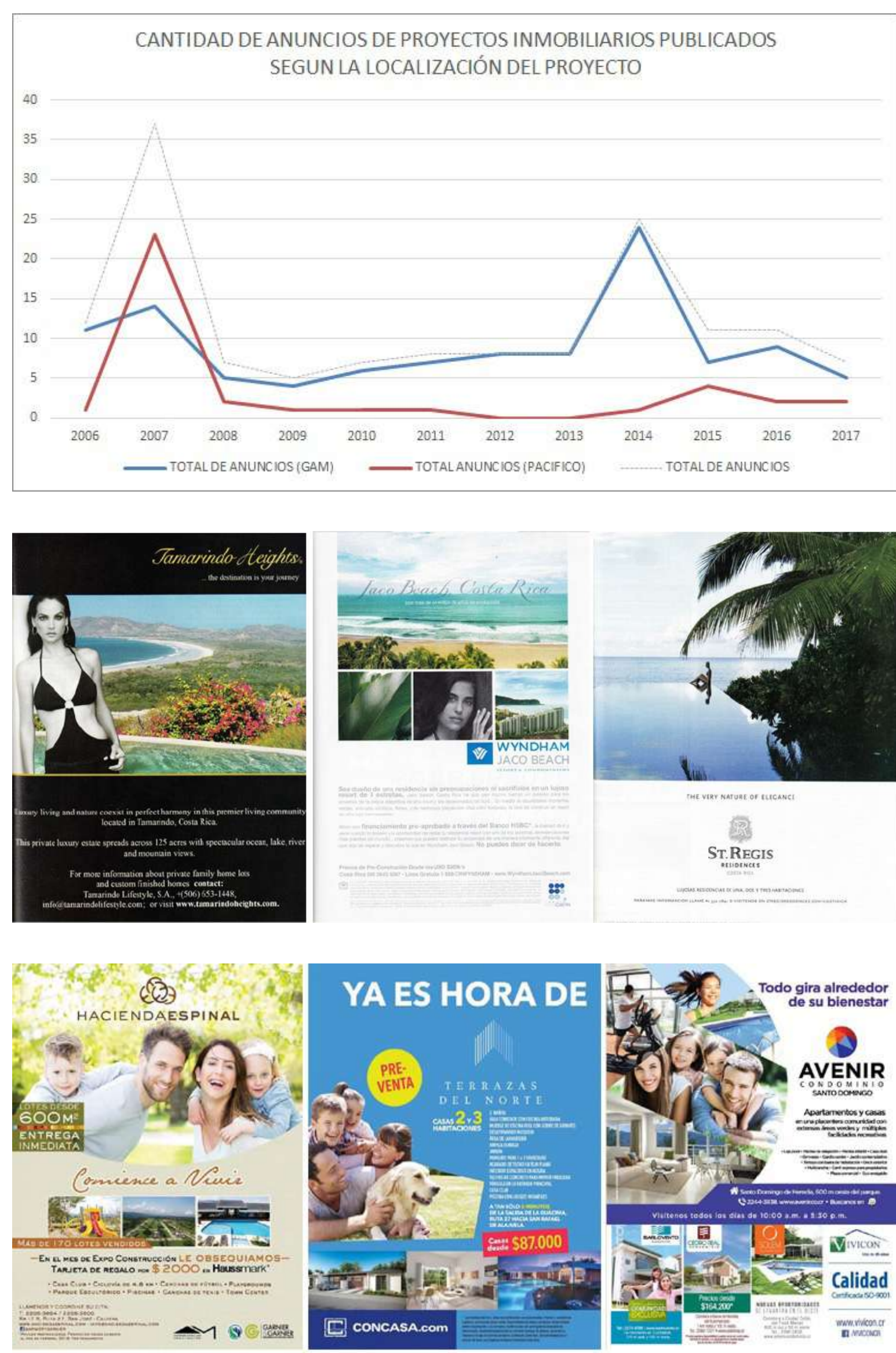

El desplazamiento de la actividad de los mercados inmobiliarios del litoral Pacífico Norte y Central a las zonas urbanas de la Gran Área Metropolitana ha sido una tendencia ampliamente señalada en los Informes Nacionales de la Situación de la Vivienda y Desarrollo Urbano que emite la Fundación Promotora de Vivienda (FUPROVI). En estas publicaciones, se argumenta que la disminución de la actividad de los mercados inmobiliarios en la zona costera del Pacífico Norte y Central obedeció al impacto de la crisis económica mundial de finales del 2008, momento de inestabilidad que afectó la industria de la construcción en Costa Rica a partir del 2009 como señalan Solano y Madrigal (2009, p. 37). A partir de la consulta de dichos informes, se pueden identificar varios aspectos claves que permiten comprender la recesión del sector construcción en relación con la disponibilidad de recursos, los precios, el crédito y la construcción de viviendas:

Afectó principalmente zonas del país que aparecían con porcentajes altos de construcción de apartamentos y condominios y áreas promedio elevadas en donde el negocio de la construcción y de los bienes raíces estaba ligado a las inversiones extranjeras. Específicamente en las zonas costeras de desarrollo turístico como el Pacífico Norte y Central y en cantones de la Gran Área Metropolitana como Escazú y Santa Ana ligados a una movilidad migratoria del "turismo médico" (Solano \& 
Madrigal, 2009, p. 37; Solano \& Rojas, 2015, p. 51-98). Por ejemplo, en la provincia de Guanacaste se construyó un $24 \%$ menos en viviendas en el 2008 con respecto al 2007. Además, el total de metros cuadrados de construcción en dichas viviendas disminuyó en el mismo período un $27 \%$, dando como resultado una reducción en el tamaño promedio de las viviendas construidas (Solano \& Rojas, 2009, p. 40).

Se reflejó en construcciones con lentos grados de avance, paralizadas y abandonadas (Solano \& Madrigal, 2009, p. 37) y en el despido de más de 13.000 empleados del sector construcción entre el 2008 al 2009 (Instituto Nacional de Estadística y Censos, 2008-2009; Solano \& Rojas, 2010, p. 8).

Descendió la cantidad de permisos para construcción de vivienda nueva de 28.189 unidades en el 2007 a 26.711 unidades en el 2008 , que representa una caída de un 5\% (Solano \& Madrigal, 2009, p. 37).

Disminuyó la cantidad total de metros cuadrados de construcción de vivienda nueva, declive de poco más de 100.000 metros cuadrados (Solano \& Madrigal, 2009, p. 37).

- Se redujo la oferta de crédito de vivienda y se endurecieron las condiciones de financiamiento ante la incertidumbre y falta de liquidez de la economía costarricense en el 2009 (Solano \& Rojas, 2010, p. 12).

Bajó la cantidad de viviendas construidas, así como de los metros de construcción promedio por vivienda en cantones con mejor Índice de Desarrollo Humano (IDH). En otras palabras, impactó el mercado inmobiliario orientado a sectores de ingresos medios altos y altos, dadas las características de las viviendas que se dejaron de construir. Para el año 2009, se contabilizó una disminución de 36,6\% de la vivienda construida con respecto al 2008. Justamente en cantones del Pacífico Norte y Central y en cantones de la provincia de San José como Escazú, Santa Ana y otros de la provincia de Heredia que habían presentado un aumento importante y sostenido de la cantidad de construcciones residenciales durante los primeros años de la presente década (Solano \& Rojas, 2010. p. 13-28).

El déficit de vivienda que tiene el país y, por ende, la necesidad de primera vivienda, ha mantenido activas las empresas dedicadas a la construcción a pesar de la recesión en el sector construcción, especialmente en la Región Central, donde el déficit es considerablemente alto con respecto a las otras regiones. El mercado urbano, que es numeroso y estable, ha facilitado que las empresas mantuvieran una circulación de capital amplia y constante. La inversión en espacios urbanos, mucho más segura y versátil que la inversión en espacios de sol y playa, explica que, a partir de la crisis económica del 2008, se haya dado una relocalización de la inversión inmobiliaria de las costas a la ciudad.

Mientras que el mercado inmobiliario habitacional de lujo se encontró detenido para el 2010, impactando los polos turísticos del país (Chacón, 2010), el mercado inmobiliario para el segmento urbano ha experimentado un auge caracterizado por los proyectos con tipología de apartamentos y condominios, la emergencia de las miniciudades, el dinamismo del mercado de vivienda desarrollada por el sector privado para el segmento medio y alto, la puesta en marcha de una maquinaria de reactivación de la actividad inmobiliaria entre bancos, desarrolladores y ferias de vivienda, que se manifestó en una propensión hacia la densificación selectiva y verticalización diferenciada del crecimiento urbano como se explora a continuación.

\section{Nuevas verticalidades y densidades}

El escenario que legó la crisis muestra el predominio de la tipología de apartamentos y condominios, como se observa en la Figura 7. Mientras que las construcciones tipo casas particulares decrecieron en un $5.9 \%$ con respecto a la cantidad total de soluciones, las de apartamentos y condominios crecieron en un $24 \%$ dando como resultado que este segundo tipo de construcciones haya aumentado su participación relativa en el total de construcciones residenciales. Si en el año 2010 los apartamentos y condominios representaban un $12.1 \%$ del total de construcciones residenciales, en el 2012 ese porcentaje creció hasta un 19.2\% (Solano \& Rojas, 2013, p.48). 
Figura 7. Permisos de construcción residencial y porcentaje según destino de la obra, 20002012. Fuente: FUPROVI (2013)
Figura 8. Cantidad de publicidad inmobiliaria por tipología de proyecto y ubicación según cantón. Fuente: Elaboración propia a partir de la sistematización de los anuncios de publicidad de proyectos inmobiliarios publicados en la Revista Summa entre el 2006 - 2017.

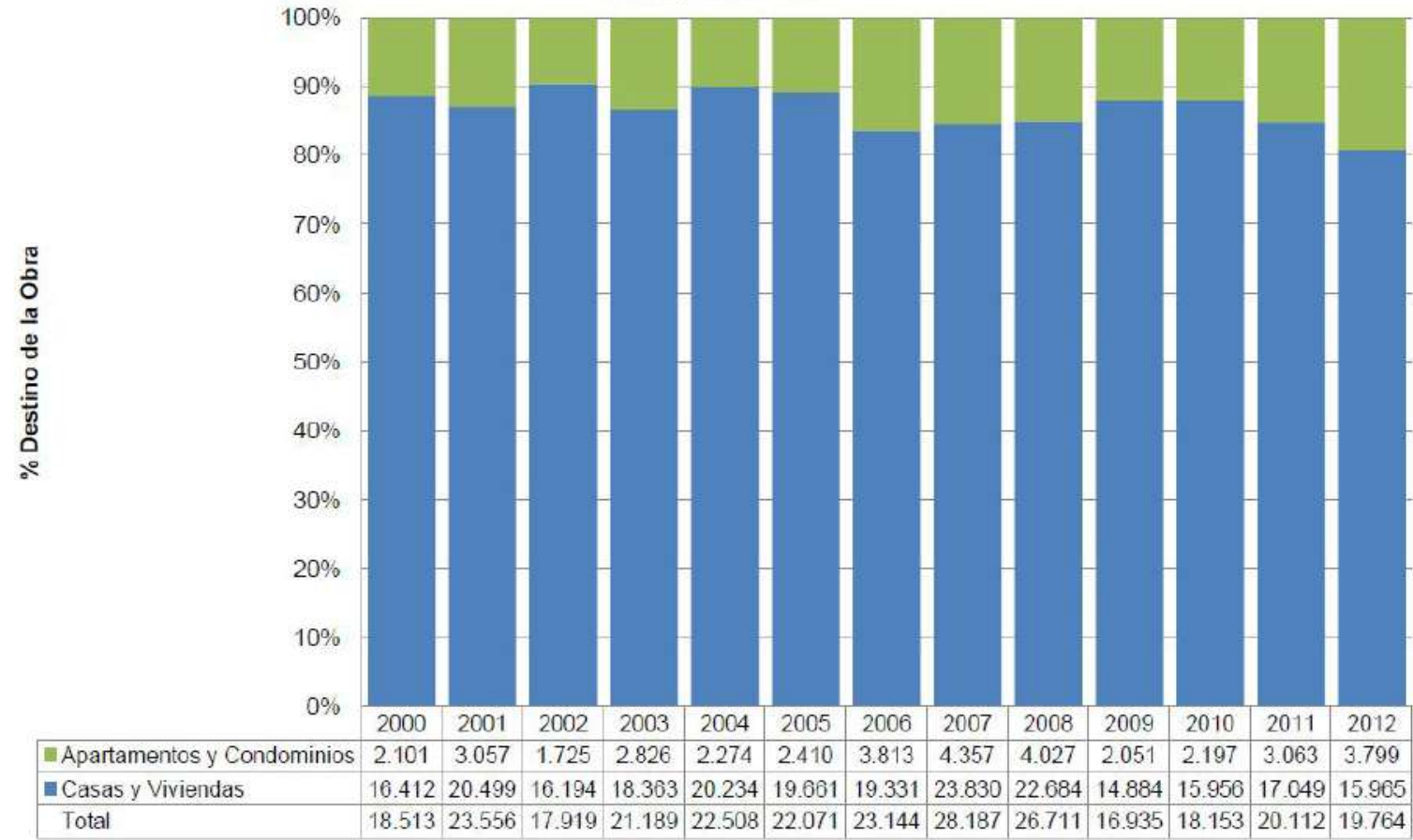

El aumento del precio de la tierra y el congestionamiento vial favorecieron la emergencia de proyectos inmobiliarios de uso mixto que combinan vivienda, oficinas y comercio, y de esta forma ofrecen a las personas la opción de mezclar actividades como el trabajo, el descanso, el entretenimiento, el consumo y la educación en lugares con altos niveles de seguridad, diseño arquitectónico y buenos entornos de ubicación (Quirós, 2013). La oferta de proyectos mixtos, en ocasiones denominados "miniciudades" (Acosta, 2017), tomó fuerza al interior de la Gran Área Metropolitana, empero, con mayor intensidad en los cantones de Escazú, Santa Ana y Belén, cantones ubicados al oeste (Solano \& Rojas, 2013, p. 107). Esta tendencia concuerda con los resultados que muestra el estudio de la publicidad inmobiliaria en la Figura 8.

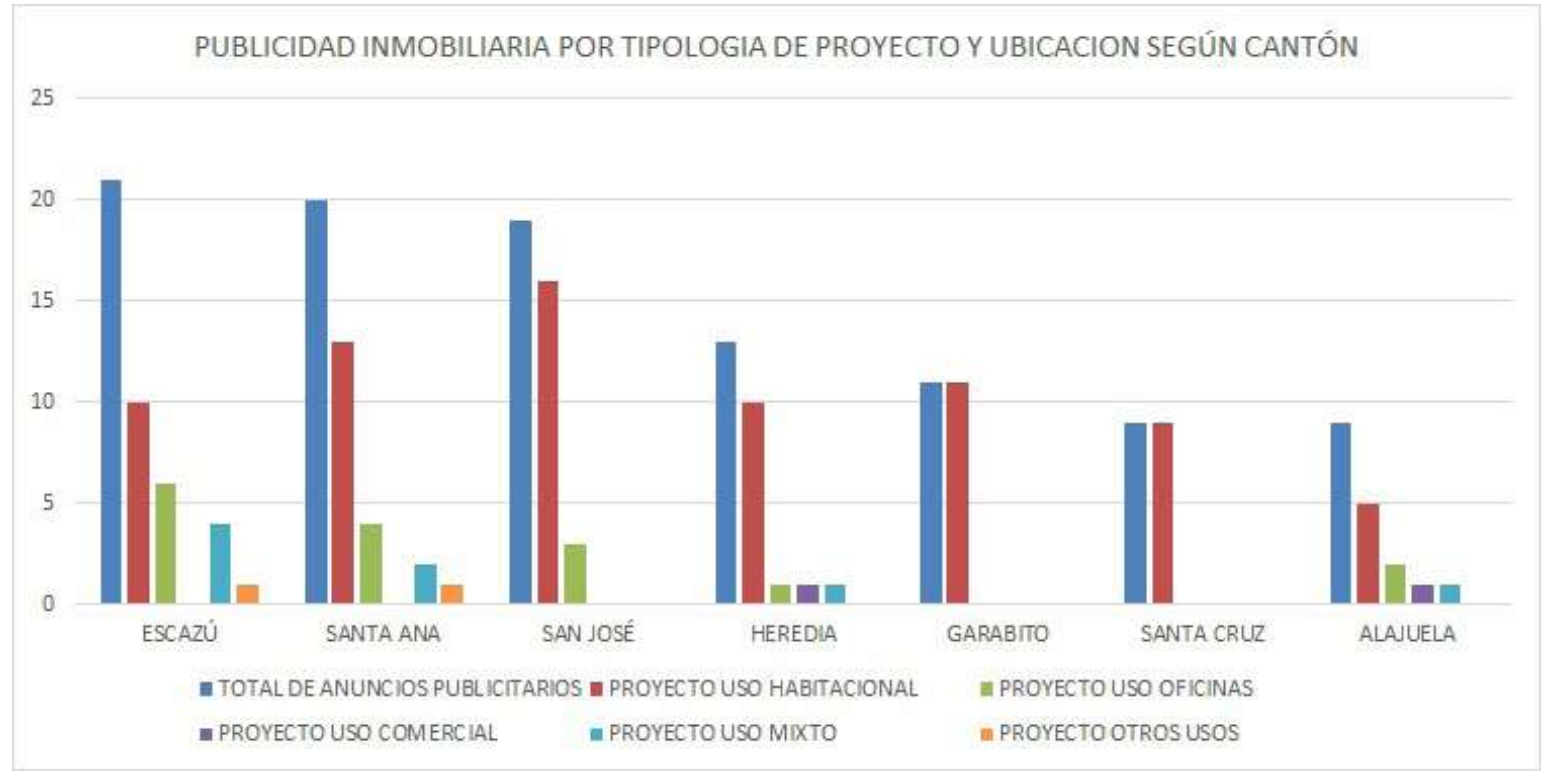

En un escenario de crisis, se evidencia un fuerte dinamismo en la construcción de vivienda en cantones con un Índice de Desarrollo Humano (IDH) alto como Escazú, Curridabat, Santa Ana, Montes de Oca, Heredia, Belén, Flores y San Pablo, todos dentro de la Gran Área Metropolitana (Solano \& Rojas, 2010, p. 28). Específicamente, el crecimiento en la construcción de vivienda entre el 2012 y el 2014 fue posible por medio de la actividad del mercado inmobiliario y del sector financiero, contrario a lo sucedido años atrás, sustentado por los subsidios estatales (Solano \& Rojas, 2015, p. 46), tendencia que se manifiesta en la concentración de proyectos con un precio en el rango de los (USD) $\$ 100.000$ a los (USD) $\$ 200.000$, dos terceras partes de la oferta de soluciones habitacionales a la venta, como se observa en la Tabla 1 y en la Figura 9.

En el 2010, año en el que el momento más crítico de la crisis había pasado, se conformó una iniciativa de reactivación de la actividad inmobiliaria entre bancos, desarrolladores y promotores de ferias de vivienda. Desde finales del 2010 y hasta principios del 2011, varios grupos financieros idearon una serie de productos y alianzas para dinamizar los segmentos de préstamos hipotecarios que consideraron seguros y cómodos. Dentro de las medidas se incluyeron menos restricciones para las nuevas modalidades de préstamos hipotecarios como la opción de créditos de un $100 \%$ del valor de la vivienda 
Tabla 1. Proyectos y soluciones habitacionales según el precio de cada solución. Fuente: FUPROVI (2012).

\begin{tabular}{|c|c|c|c|c|c|}
\hline $\begin{array}{c}\text { Precio aproximado de la solución } \\
\text { habitacional (miles de \$) }\end{array}$ & \multicolumn{2}{|c|}{ Proyectos } & \multicolumn{2}{c|}{$\begin{array}{c}\text { Soluciones habitacio- } \\
\text { nales }\end{array}$} & $\begin{array}{c}\text { Promedio de } \\
\text { Soluciones por } \\
\text { proyecto }\end{array}$ \\
\hline$<\operatorname{de} \$ 100$ & 8 & $10,10 \%$ & 1.140 & $14,80 \%$ & 143 \\
\hline Entre \$ 100 y \$200 & 49 & $62,00 \%$ & 4.945 & $64,00 \%$ & 101 \\
\hline$>\operatorname{de} \$ 200$ & 11 & $13,90 \%$ & 833 & $10,80 \%$ & 76 \\
\hline N/D & 11 & $13,90 \%$ & 806 & $10,40 \%$ & 73 \\
\hline Total & $\mathbf{7 9}$ & $\mathbf{1 0 0 , 0 0 \%}$ & $\mathbf{7 . 7 2 4}$ & $\mathbf{1 0 0 , 0 0 \%}$ & $\mathbf{9 8}$ \\
\hline
\end{tabular}

-Proyectos - -Soluciones habitacionales

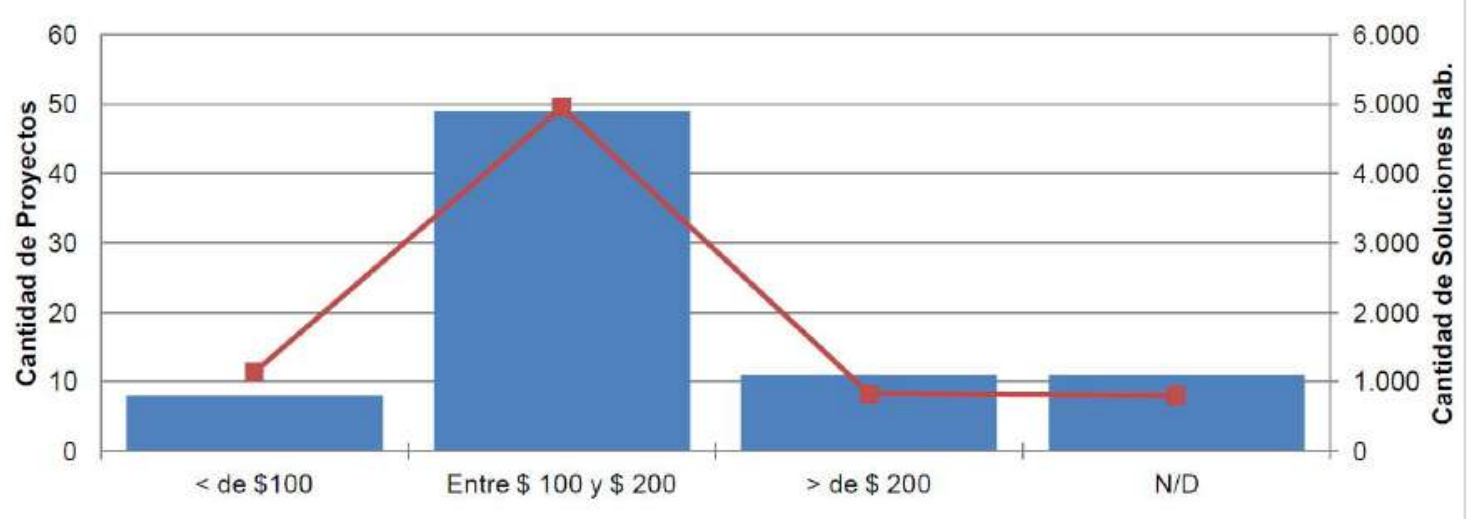

que ofreció el Banco de Costa Rica o el financiamiento del inventario de vivienda disponible con programas de tasa fija para sanear el mercado, financiamiento de la prima, financiamiento de los costos de formalización y estudios de peritaje de valor de la propiedad (Revista Summa, 2011, p. 84). Inclusive para el 2011, se promovió una mayor oferta de financiamiento en dólares, ya que los bancos centroamericanos tuvieron suficiente liquidez en esa moneda y el costo internacional fue bajo debido a la devaluación del dólar (Revista Summa, 2011, p. 84).

En este momento se reconoció un segmento sólido y renovado de población meta y a la cual se orientaron dichos productos financieros. En este caso, se trata de parejas de profesionales jóvenes que buscan financiamiento para la compra de la primera vivienda dentro de las zonas metropolitanas y que tienen morosidad baja y capacidad de endeudamiento por montos que resultaron atractivos para la rentabilidad de los bancos. No obstante, los bancos e instituciones financieras no solo diseñaron productos financieros para futuros compradores, sino que realizaron alianzas estratégicas con los propios desarrolladores inmobiliarios de forma tal que las soluciones de vivienda ofrecieron facilidades de financiamiento con el propio banco, que además asumió la deuda inicial del proyecto. Estas alianzas entre bancos y grandes desarrolladores provocaron que los pequeños desarrolladores inmobiliarios salieran del mercado a partir de la crisis económica (Revista Summa, 2011, p. 86).

\section{Medios e imágenes publicitarias}

En esta coyuntura, los bancos e instituciones financieras invirtieron en campañas publicitarias para incentivar que la población meta se decidiera a solicitar préstamos de vivienda (Revista Summa, 2011, p. 86). Esta tendencia se ve reflejada en los resultados de la sistematización y localización georeferenciada de los proyectos inmobiliarios publicitados a lo largo de 10 años en la Revista Summa. Considerando la Figura 10 y la Figura 11, se puede afirmar que la provincia de San José es donde se ofrece la mayor cantidad de proyectos inmobiliarios en general. Y, en específico, concentra la publicidad para el segmento de vivienda y proyectos de uso mixto. Cuando se disgregan los datos por cantón, como lo muestra la Figura 12, se concluye que los tres cantones de mayor actividad de los mercados inmobiliarios urbanos son San José, Santa Ana y Escazú.

Sobre el análisis del comportamiento de los mercados inmobiliarios, considerando la publicidad inmobiliaria, se pueden realizar dos observaciones. En primer lugar, la relocalización de la inversión inmobiliaria señala, como se observa en la Figura 13 y en la Figura 14, que a partir del 2007, ocurre un descenso de la promoción de proyectos inmobiliarios del segmento costero y que, para el 2014, la promoción de proyectos se concentra en la Gran Área Metropolitana. 
Figura 10. Cantidad de anuncios publicitarios según la ubicación del proyecto por provincia. Fuente: Elaboración propia a partir de la sistematización de los anuncios de publicidad de proyectos inmobiliarios publicados en la Revista Summa entre el 2006 - 2017.

Figura 11. Cantidad de anuncios publicitarios por tipología de proyecto según provincia. Fuente: Elaboración propia a partir de la sistematización de los anuncios de publicidad de proyectos inmobiliarios publicados en la Revista Summa entre el 2006 - 2017

Figura 12. Cantidad de anuncios publicitarios por ubicación del proyecto según cantón. Fuente: Elaboración propia a partir de la sistematización de los anuncios de publicidad de proyectos inmobiliarios publicados en la Revista Summa entre el 2006 - 2017.

Figura 13. Cantidad de anuncios publicitarios para proyectos ubicados en la región del pacífico según año de publicación. Fuente: Elaboración propia a partir de la sistematización de los anuncios de publicidad de proyectos inmobiliarios publicados en la Revista Summa entre el 2006 - 2017.
CANTIDAD DE ANUNCIOS PUBLICITARIOS SEGÚN UBICACIÓN DEL PROYECTO POR PROVINCIA
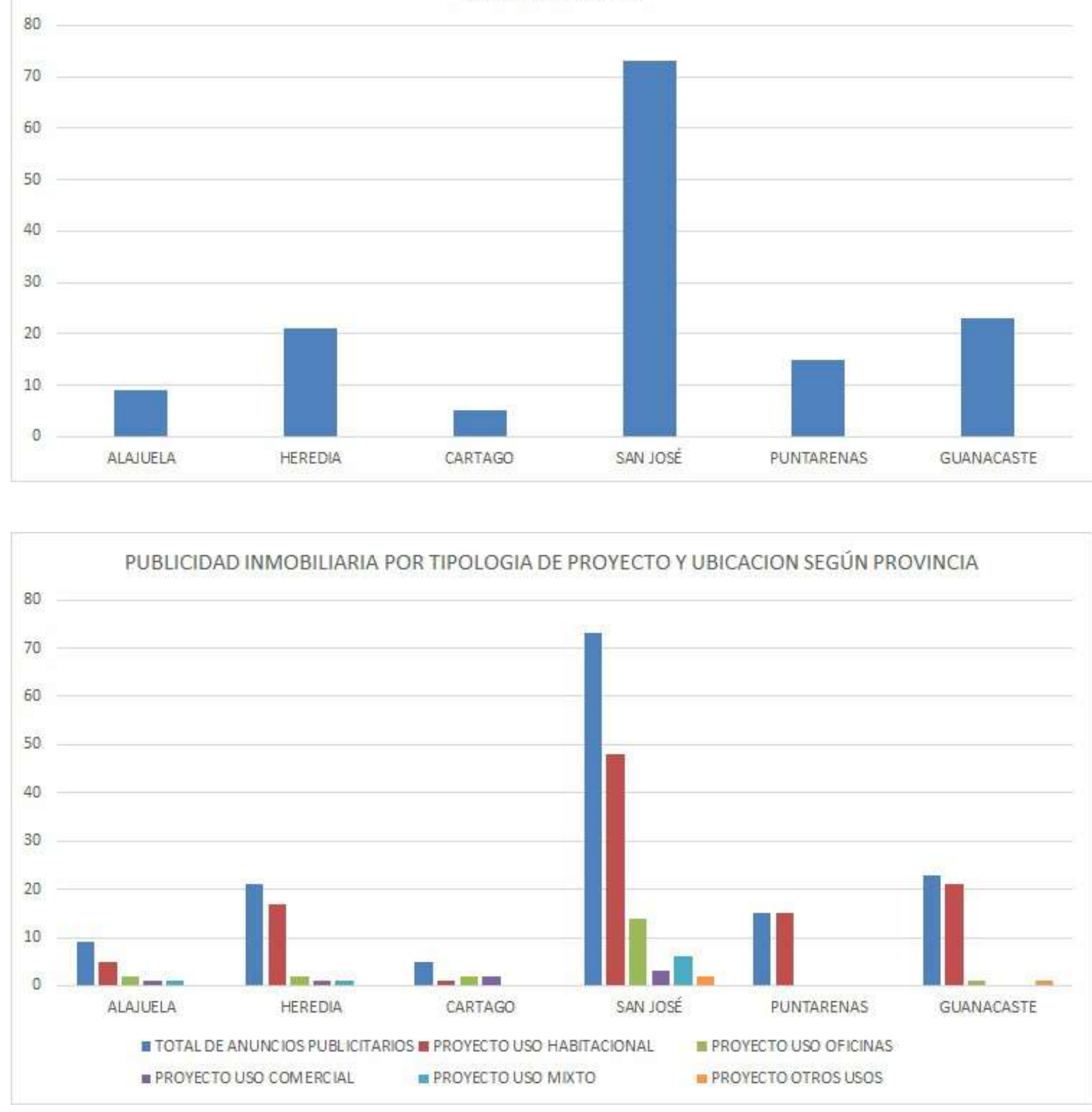

CANTIDAD DE ANUNCIOS PUBLICITARIOS SEGÚN UBICACIÓN DEL PROYECTO POR CANTÓN

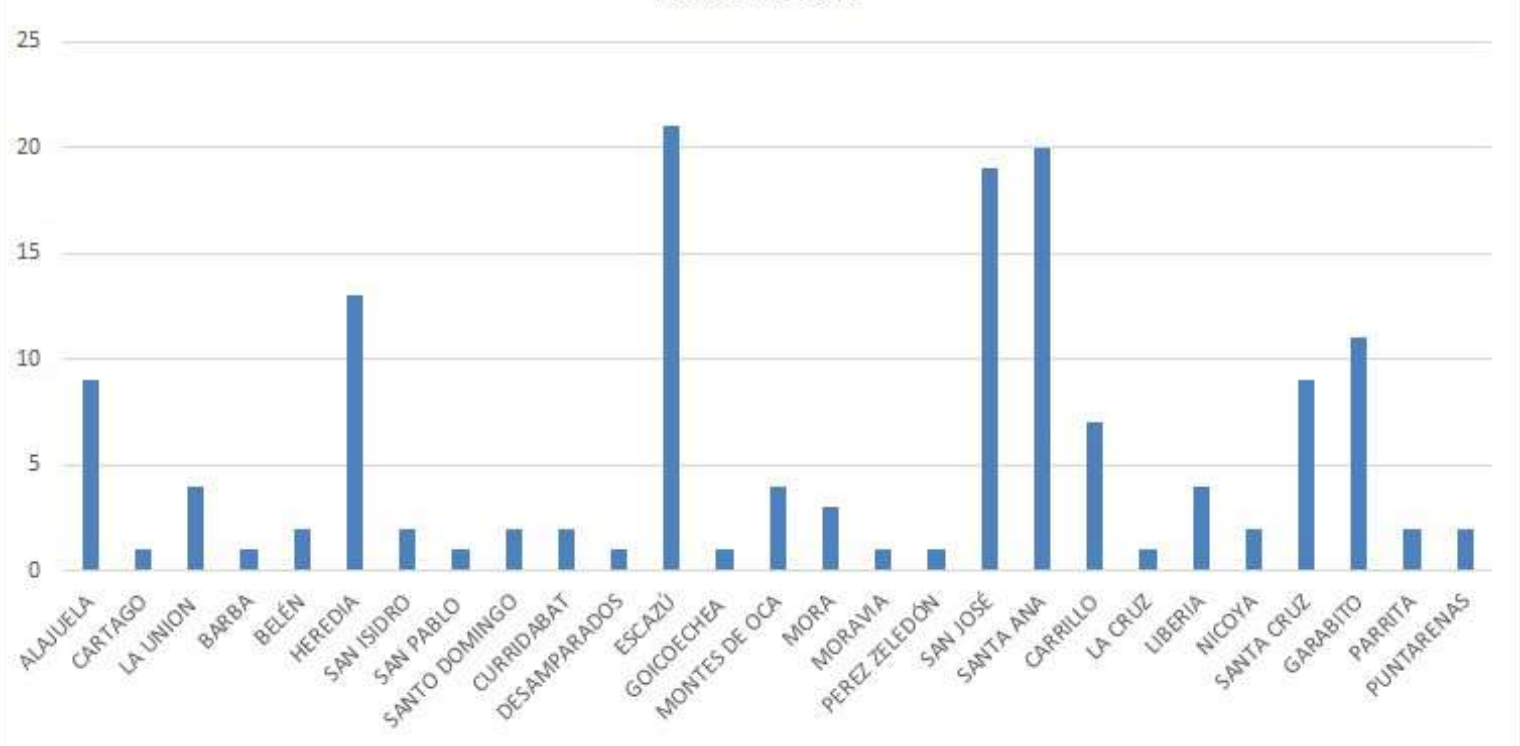

ANUNCIOS PUBLICITARIOS PARA REGION DEL PACIFICO POR TIPO DE PROYECTO SEGÚN AÑO DE PUBLICACIÓN

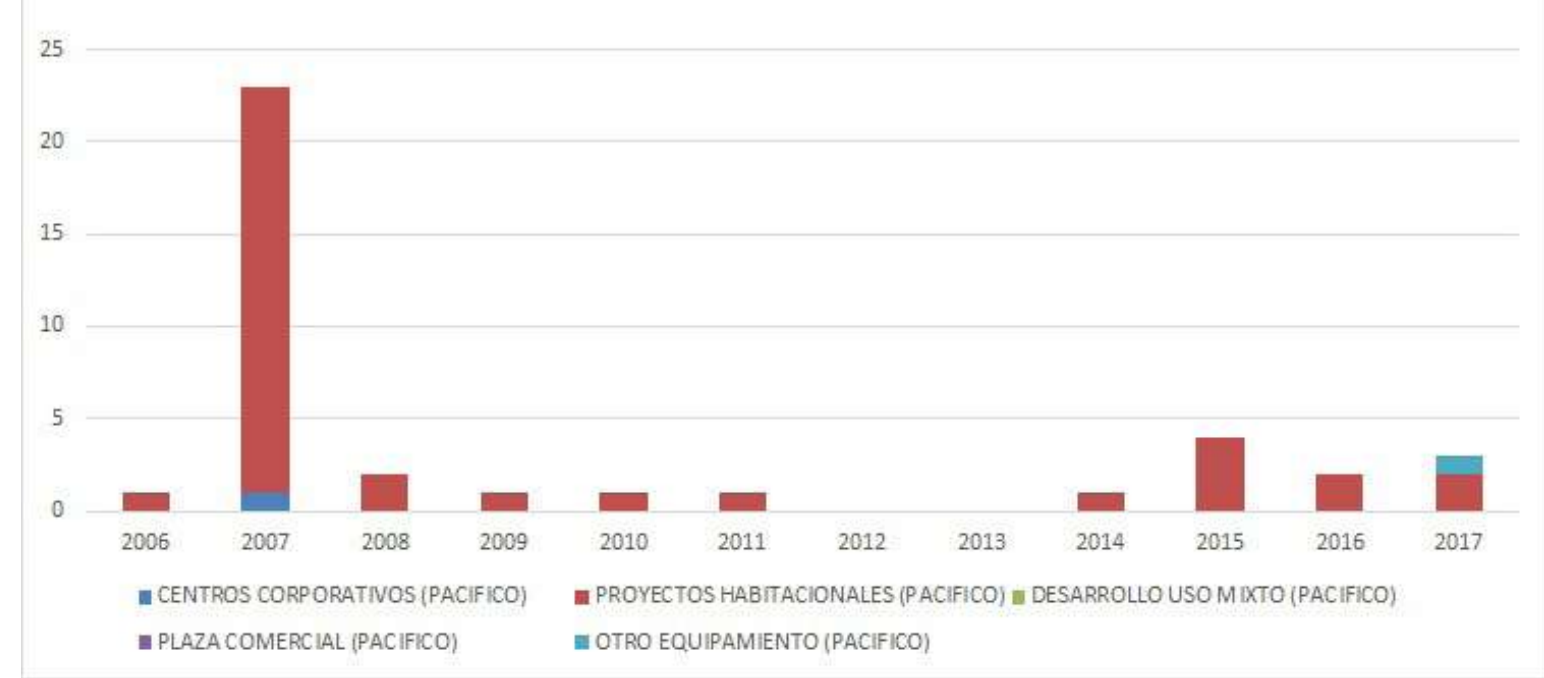


Figura 14. Cantidad de anuncios publicitarios para proyectos ubicados en GAM según año de publicación. Fuente: Elaboración propia a partir de la sistematización de los anuncios de publicidad de proyectos inmobiliarios publicados en la Revista Summa entre el $2006-2017$.
Figura 15. Cantidad de proyectos inmobiliarios publicitados en la revista Summa con publicidad en Internet. Fuente: Elaboración propia a partir de la sistematización de los anuncios de publicidad de proyectos inmobiliarios publicados en la Revista Summa entre el 2006 - 2017.

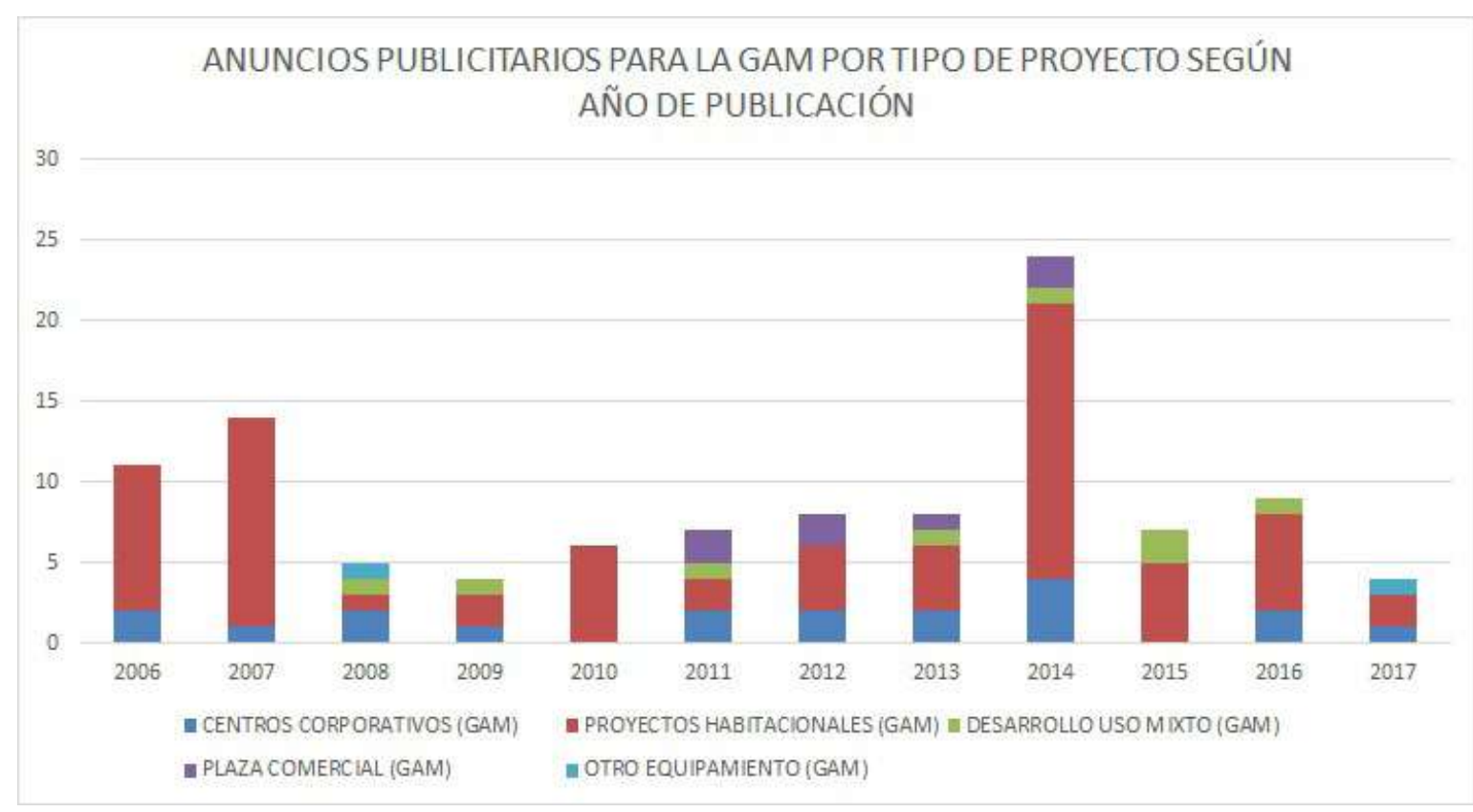

En segundo lugar, la transformación de las maniobras publicitarias en el contexto posterior a la crisis económica y en favor de una intensificación de la explotación del suelo urbano. La Figura 15 muestra que a partir del 2007 se reduce la cantidad de proyectos que no contaban con algún tipo de publicidad en Internet y, entre el 2013 y 2014, la muestra señala una mayor cantidad de proyectos con presencia en al menos 3 medios de difusión de carácter digital.

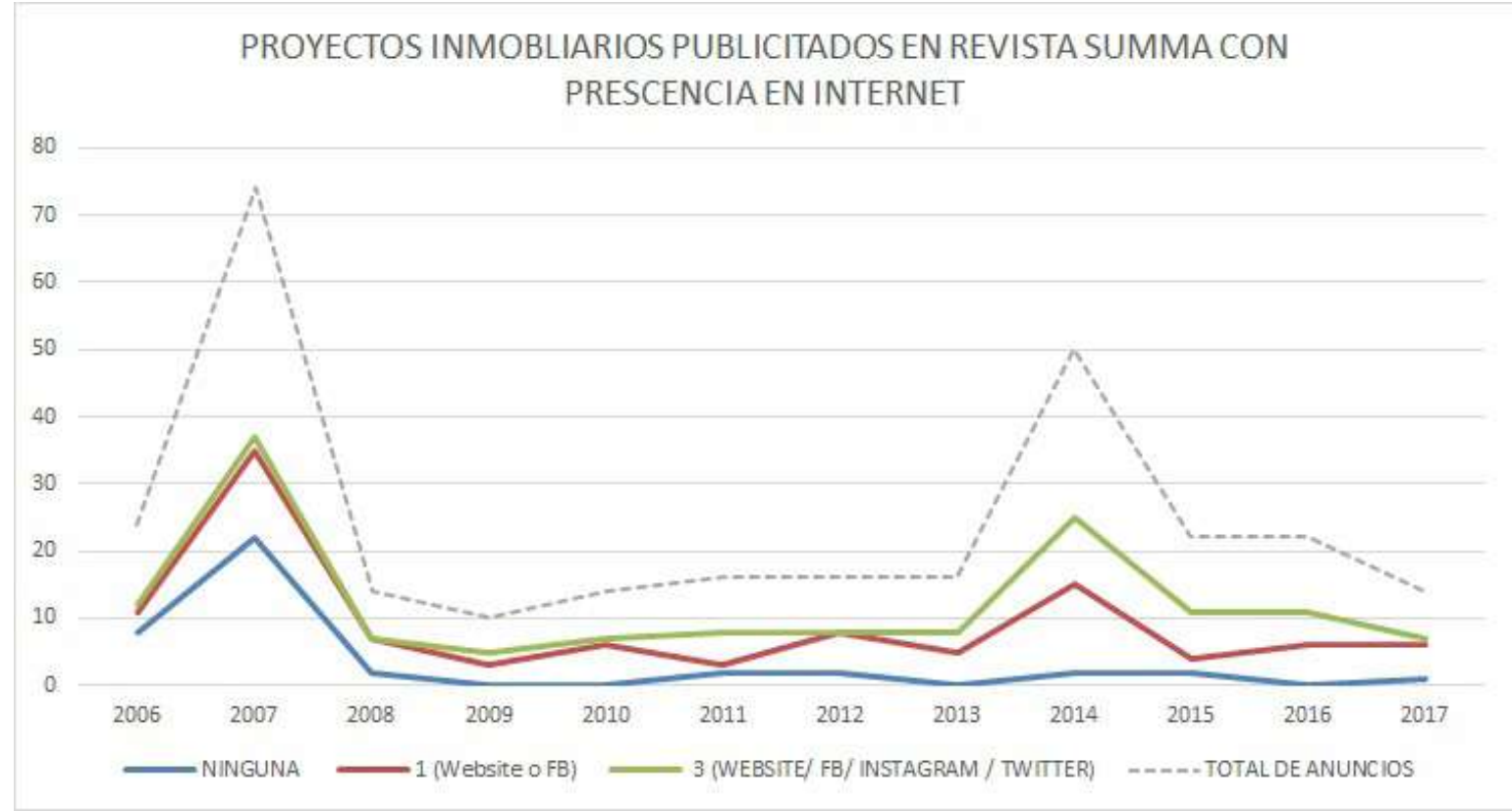

Existe, además, un paso de la publicidad inmobiliaria de los medios impresos tradicionales hacia los medios digitales y, concretamente, hacia la presencia de información de proyectos en sitios web o mediada por redes sociales. De esta apuesta se puede inferir el segmento de población al que se dirige, como ya vimos, la actividad del mercado inmobiliario urbano, concentrando sus operaciones en cantones de la provincia de San José como Santa Ana y Escazú.

Cuando se contrasta el comportamiento de la publicidad inmobiliaria con la situación particular de los cantones, se observa en la Figura 16 y la Figura 17, que los cantones que ocupan las primeras posiciones en el Índice de Competitividad Cantonal (ICC), Escazú y Santa Ana, son los mismos cantones en donde se promocionan la mayor cantidad de proyectos inmobiliarios y los mismos que tienen un porcentaje bajo de población en pobreza extrema. El cantón de San José es una excepción, ya que posee la mayor desigualdad de los tres cantones activos en negocio inmobiliario, empero cuenta con los valores de un centro político, administrativo y comercial.

Para el 2012, la llegada masiva de empresas con capital transnacional supuso una expansión comercial e industrial que se logra traducir en el auge del negocio inmobiliario en las principales ciudades de Centroamérica. Las demandas por tener estilos de vida cosmopolitas, sofisticados y seguros se manifestaron en la proliferación de apartamentos en altura para familias o ejecutivos jóvenes que demandaban construcciones modernas que, en términos de tecnología y diseño, estuvieran al nivel de las mejores ciudades del mundo (Revista Summa, 2012, p. 86). Los incentivos para el financiamiento, sumados a 
Figura 16. Relación entre el índice de competitividad cantonal y la cantidad de publicidad inmobiliaria por ubicación del proyecto según cantón. Fuente: Elaboración propia a partir de la sistematización de los anuncios de publicidad de proyectos inmobiliarios publicados en la Revista Summa entre el 2006 - 2017 y los datos del Informe de Índice de competitividad cantonal 2011- 2016 del Observatorio del Desarrollo de la Universidad de Costa Rica.

Figura 17: Porcentaje de población con 4 carencias según cantón. Fuente: Elaboración propia a partir de datos del Censo 2011, INEC. la apertura bancaria y proyectos estatales de renovación urbana, constituyeron factores claves que explican la tendencia hacia la verticalización y densificación selectiva en Costa Rica (Chacón, 2010).
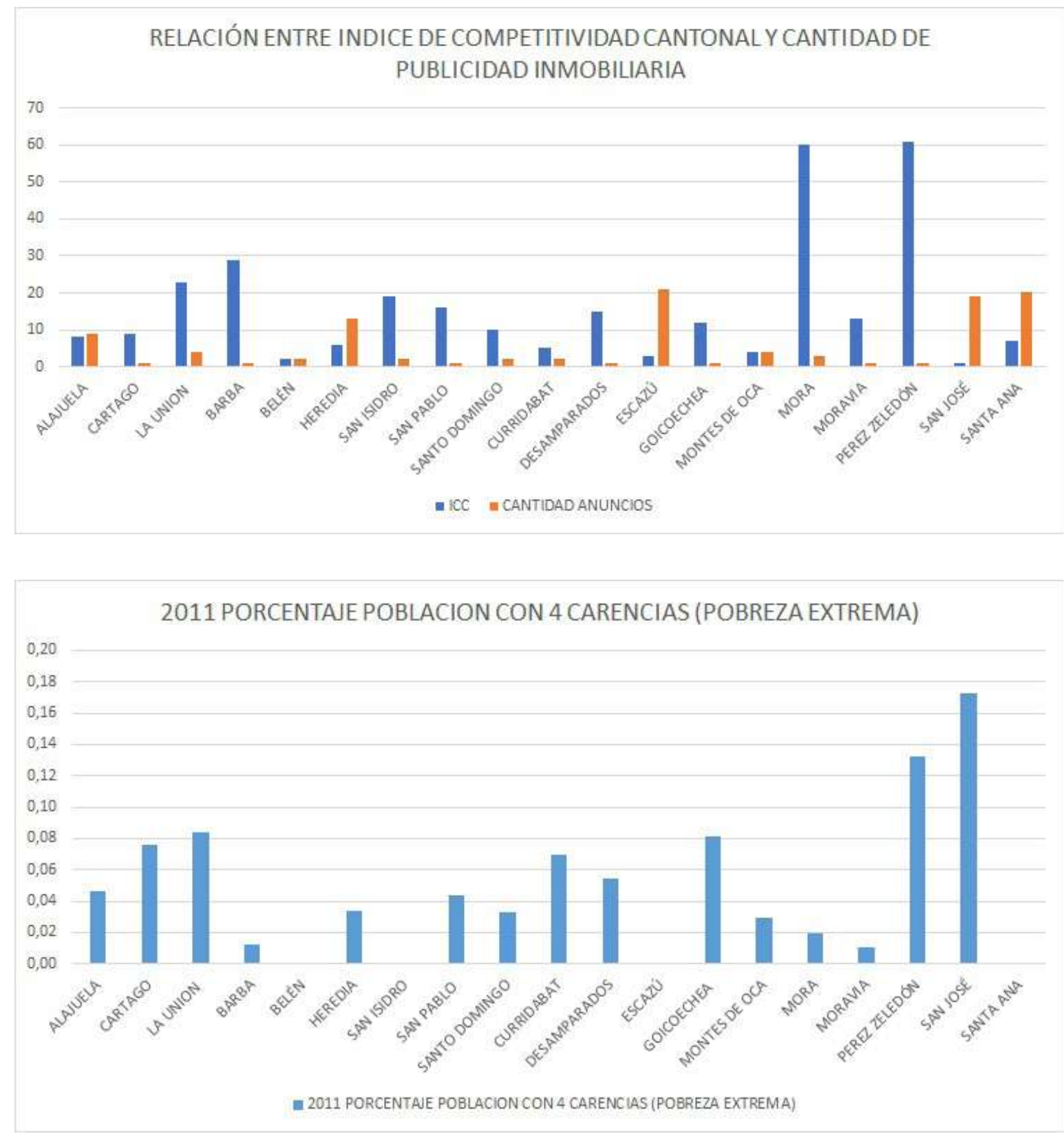

\section{Conclusiones}

El texto, siguiendo el llamamiento coyunturalista de Stuart Hall, realizó una aproximación del contexto que posibilitó, desde 1980 a 2017, la emergencia de la ciudad neoliberal en Costa Rica. Para esto, se abordaron un conjuntos de articulaciones que produjeron, bajo una situación concreta, la especificidad de dicho fenómeno. Esto implicó realizar una revisión bibliográfica que, sin ser totalmente exhaustiva, permitió identificar panoramas nacionales en materia política, económica, territorial y urbana. Además, se extrajeron informaciones valiosas de revistas, por ejemplo, de notas periodísticas e imágenes publicitarias.

Este acercamiento comprendió la ciudad neoliberal como el resultado de un conjunto de prácticas que encarnan no una iniciativa unidimensional, sino un modelo de gestión urbana conducido por diversos actores. En este sentido, se delimitaron tres condiciones de la ciudad neoliberal: i) la neoliberalización profunda provocada por el Estado, la creación de programas aperturistas y la atracción de Inversión Extranjera Directa; ii) la reestructuración socioespacial de la Gran Área Metropolitana que incidió en la polarización del desarrollo en un eje este-oeste; iii) la intensificación de la actividad inmobiliaria por nuevas prácticas publicitarias alrededor de la vivienda en la ciudad.

Del primer apartado, "Apunte I. La neoliberalización profunda (1980-2000)", se concluye que, gracias a diversas prácticas políticas y económicas (marcos institucionales, programas estatales, prácticas regulatorias y desregulatorias), el proyecto neoliberal se afianzó progresivamente desde la década de los ochenta en Costa Rica. Este proceso multiescalar aseguró, recientemente, la atracción de Inversión Extranjera Directa por medio de la instalación de empresas transnacionales en el país. Las políticas para el desarrollo de ventajas competitivas territoriales justificaron, precisamente, 
modificaciones de las normativas fiscales, la flexibilización de las condiciones de contratación de trabajadores y la creación de agencias gubernamentales que operan bajo mecanismos de apalancamiento público-privado.

Se entiende que dentro de las maniobras para crear estas ventajas competitivas territoriales se incluyen no solo la reestructuración institucional (acción prototípica del re-escalamiento del Estado), sino también la reestructuración socio-espacial (acción prototípica del re-escalamiento de la urbanización). Es aquí donde se plantea que ambas acciones han devenido mecanismos para efectuar los ajustes que conlleva la neoliberalización, y así resolver en la ciudad las tensiones entre la economía local, nacional y transnacional.

Del segundo apartado, "Apunte II. Las dinámicas de reestructuración socio-espacial (2000-2017)", se concluye que, si bien las políticas de reestructuración neoliberal no son recientes, si lo son sus expresiones espaciales, que se constatan por la acelerada intervención de ciertas zonas de la Gran Área Metropolitana. Esto ha sido fundamental para consolidar un eje de acumulación este-oeste que concentra, actualmente, la riqueza en unas cuantas localizaciones puntuales y dentro de unos cuantos sectores restringidos de población, generando una serie de "archipiélagos" donde se reinscribe el espacio en términos de clase: "islas residenciales", "islas de riqueza", "islas de consumo", "islas laborales", "islas productivas", "islas de miseria", "islas de exclusión", entre otras.

Esta urbanización neoliberal en Costa Rica se diferencia claramente de anteriores procesos de urbanización, tanto en el tipo de formaciones urbanas que empiezan a predominar (zonas residenciales en condominio, zonas comerciales o corporativas, zonas industriales y de exportación, centros interempresariales y clúster tecnológicos) como en el despliegue inusual de unos estrategias publicitarias asociados a la actividad de los mercados inmobiliarios urbanos. Entonces, los procesos de neoliberalización se vuelven tangibles tanto en la proliferación de formaciones urbanas como en la constitución de mercados inmobiliarios y en la promoción de nuevos estilos de vida que estos realizan.

Del tercer apartado, "Apunte III. La intensificación de la actividad inmobiliaria urbana (2006-2017)", se concluye que, a partir de la crisis económica del 2008, existe una intensificación de la actividad inmobiliaria cuyo objetivo claramente no es mercado de las costas, sino el mercado urbano. Esto marca una tendencia hacia la verticalización y densificación selectiva mediante proyectos que agudizan las desigualdades en el mencionado eje este-oeste de la Gran Área Metropolitana. En este cambio, los mercados inmobiliarios logran agrupar y conectar un grupo de actores privilegiados, locales y globales, que favorecen el desarrollo y el crecimiento de la ciudad.

Actores privilegiados en tanto son, actualmente, los encargados de controlar, con amplio margen de operación, el territorio por medio operaciones de acumulación de capital y de la mercantilización de la experiencia. Todo esto supone reconocer el carácter cultural de la ciudad neoliberal. Un conjunto de ideologías, intereses y objetivos que plasman en el espacio urbano sistemas de razonamientos que oscilan entre la organización de la infraestructura y la producción matrices de sentido. Para esto, la publicidad aparece como técnica que incentiva estilos de vida, identidades de consumo y rituales de exclusividad.

\section{Referencias Bibliográficas}

Abramo, P. (2003a). A cidade da informalidade. O desafio das cidades latinoamericanas.

Abramo, P. (2003b). A dinâmica do mercado imobiliário e a mobilidade residencial nas favelas do Rio de Janeiro: resultados preliminares. [Informe de investigación]. Río de Janeiro: Instituto de Planeación Urbana y Regional (IPPUR) de la Universidad Federal de Río de Janeiro (UFRJ).

Abramo, P. (2012). "La ciudad com-fusa: mercado y producción de la estructura urbana en las grandes metrópolis latinoamericanas". EURE, 38 (114), 35-69. 
Acosta, A. (2006). "América Central: de los proyectos revolucionarios al neoliberalismo dependiente (1960-2004)". Boletín Americanista, 56, 7-33.

Acosta, S. (2017) "Revisión epistemológica de nuevas tipologías urbanas para la identificación de miniciudades en América Central" RevistArquis, 6 (2), 28-41.

Alvarado Alcázar, A. (2016). "Cerrando espacios, abriendo brechas. Urbanizaciones cerradas en San Rafael de Escazú, Costa Rica”. RevistArquis, 5 (1), 1-23.

Alvarado, A. \& Jiménez, G. (2013). Urbanizaciones cerradas en Costa Rica: transformaciones socio-espaciales en la urbanidad y segregación socio-residencial en el distrito de San Rafael de Escazú (1990-2012). (Tesis de Licenciatura en Sociología). San José, Universidad de Costa Rica.

Alvarenga, P. (2005) De vecinos a ciudadanos: movimientos comunales y luchas cívicas en la historia contemporánea de Costa Rica. Heredia, EUNA.

Becklake, S. (2014). "NGO's and the making of "development tourism destinations" The case of "destino Guatemala". TW: Zeitschrift Fuer Tourismuswissenschaft, 6(2), 223-242.

Berger, M.T. (1997). "The Reconquest of Central America: Latin American Studies and the Transition to Democracy, 1979-1990". Latin American Perspectives, 24 (1), 7-72. Recuperado de http://www.jstor.org/stable/2634234

Berger, M.T. (2006). "From Nation-Building to State-Building: The Geopolitics of Development, the Nation-StateSystem and the Changing Global Order". Third World Quarterly, 27 (1), 5-25.

Blanco Lizano, R. (2004) "Reformas neocorporativas y disputas por el control de los recursos biogenéticos en la constitución del campo político de la biodiversidad en Costa Rica 1989-2003". (Tesis de Maestría en Sociología). Universidad de Costa Rica.

Blanco Lizano, R. (2010). "Partidos políticos, redes corporativas y formación de gabinetes en Costa Rica: 1986-2010." Revista de ciencias sociales, 130, 161 172.

Blanco Lizano, R. (2010a) "Transformaciones del sector exportador costarricense en la transición del modelo de sustitución de importaciones al modelo de libre comercio: 1982-1996 estudio de caso de las redes imbricadas de agentes público-privados: CINDE-COMEX". (Tesis Doctoral en el Programa de Gobierno y Políticas Públicas). Universidad de Costa Rica.

Blanco Lizano, R. (2010b) "Tendencias corporativas en las transformaciones del Estado costarricense 1983-2008. Estudio comparativo de los sectores ambiental y exportador". Ponencia presentada al XII Congreso Centroamericano de Sociología.

Blanco Lizano, R. (2011). "Rentismo y modelo liberalizador en Costa Rica. El caso de la Fundación Omar Dengo: 1987-2009". Diálogos, Revista Electrónica de Historia, 12 (1), 35-50.

Boza, J., Chávez, D. \& Segura, I. (2015). "Observaciones. Arquitectura de condición periurbana en el GAM". (Tesis de Licenciatura en Arquitectura). Facultad de Ingeniería, Universidad de Costa Rica.

Brenner, N. (2003) "La formación de la ciudad global y el re-escalamiento del espacio del Estado en la Europa Occidental post-fordista", EURE, XXIX (86), 5-35.

Brenner, N., Peck, J. \& Theodore, N. (2010). "After neoliberalization? Globalizations, 7 (3), 327-345. DOI: 10.1080/14747731003669669

Carvajal, G. (1993). "Costa Rica en la época de los Programas de Ajuste Estructural 1985-1992. Reflexiones, 7 (1). Recuperado de http://revistas.ucr.ac.cr/index. php/reflexiones/article/view/10558/9959

Castro, C. (1995). Estado y sectores medios en Costa Rica: redimensionamiento de un pacto social. San José, Costa Rica: FLACSO

Chacón, D. (2010). "Vivienda en la antesala del amanecer". Revista Summa, 66-69. 
Chomsky, N. (2001). El miedo a la democracia. Barcelona: Crítica.

Contreras, A. (2013) Soralla de Persia: médium, medios y modernización cultural en Costa Rica (1950-1970). Heredia: EUNA.

Cordero, A. (2004). "Clases medias y movimientos sociales en Costa Rica". San José, C.R.: FLACSO. Consulta del 10 abril 2017 de http://bibliotecavirtual.clacso.org.ar/ Costa_Rica/flacso-cr/20120809032730/clases.pdf

Cuevas, R. (1996) El punto sobre la i: políticas culturales en Costa Rica, 1948-1990. San José, Ministerio de Cultura, Juventud y Deportes.

Delgado, J. (1983). El Partido Liberación Nacional: análisis de su discurso políticoideológico. San José, Costa Rica: Editorial Imprenta Nacional.

Ferman, C. (2004). Metáforas poscoloniales: restauración, desarraigo y construcción del artefacto del Cuarto Mundo en la Antigua Guatemala. En: Navia, P., Zimmerman, M. y Sassen, S. (2004). Las Ciudades latinoamericanas en el nuevo (des)orden mundial. México, D.F.: Siglo XXI, 336-48.

Flórez-Estrada, M. (s.f.) La burguesía anti-social. Mimeo. Recuperado de https://www. academia.edu/3590848/La_burgues\%C3\%ADa_antisocial

Foulds, A. (2014). Buying a colonial dream: the role of lifestyle migrants in the gentrification of the historic center of Granada, Nicaragua. (Tesis Doctorado en Filosofía). Lexington: Universidad de Kentucky.

Fürst, E. (2000a) "Préstamos y políticas de ajuste estructural frente a la crisis del endeudamiento: el caso de Costa Rica." Revista de Ciencias económicas 8 (2).

Fürst, E. (2000b) Costa Rica: cambio estructural en la economía y el ambiente, una evaluación de múltiples criterios. Heredia: EUNA.

García, G. (2011) Formación de la clase media en Costa Rica. Economía, sociabilidades y discursos políticos (1890-1950). (Tesis Maestría Académica en Historia). San José: Universidad de Costa Rica.

Gillem, M. (2009) "Make-Believe Main Streets: Hyperreality and the Lifestyle Center". Traditional Dwellings and Settlements Review TDSR 20 (2),13-26.

Grossberg, L. (2009). "El Corazón De Los Estudios Culturales: Contextualidad, Construccionismo y Complejidad". Tabula Rasa, 10, 13-48.

Hall, S. (1978). Policing the crisis: mugging, the state, and law and order. London: Macmillan.

Harvey, D. (2003) Espacios de Esperanza. Serie Cuestiones de antagonismo. Madrid: Akal.

Inzulza, J. \& López, N. (2014). "Gentrificación de escala intermedia global en Latinoamérica. El caso de la reconstrucción de Managua, Nicaragua 1972-2014". Revista de Urbanismo, 31, 56-75.

Janoschka, M. (2002) "El nuevo modelo de la ciudad latinoamericana: fragmentación y privatización". EURE Revista Latinoamericana de Estudios Urbano Regionales, 28, 85: 11-29.

Janoschka, M. (2009) "The Contested Spaces of Lifestyle Mobilities: Regime Analysis as a Tool to Study Political Claims in Latin American Retirement Destinations". Die Erde, 140(3), 251-274.

Jiménez, A. (2017). "Mall"-deando la ciudad: 24 años de territorialización de los malls en Costa Rica. RevistArquis, 6 (2), 71-85. DOI: https://doi.org/10.15517/ ra.v6i2.30604

León, A. (2012). "Algunos apuntes históricos sobre el sector financiero costarricense (1985-2007)". Anuario de Estudios Centroamericanos, Universidad de Costa Rica, 38, 213-240.

Lungo, M. (2005) "Globalización, Grandes Proyectos y Privatización de la Gestión Urbana". Urbano, 8 (11), 49-58.

Lungo, M. \& Polèse, M. (1998) Economía y desarrollo urbano en Centroamérica. San José: FLACSO 
Martí i Puig, S. (2000) "Democracia y neoliberalismo en Centroamérica: ¿Amigos o adversarios?" Congreso Latin American Studies Association. Recuperado de http://lasa.international.pitt.edu/Lasa2000/MartiiPuig.PDF

Martínez, J.E. (2011). "Centroamérica: Un balance de 20 años de neoliberalismo y de transnacionalización". Pueblos - Revista de Información y Debate, 49, 44-46.

Polèse, M. \& Lungo, M. (Coords). (1998). Economía y Desarrollo Urbano en Centroamérica. San José: FLACSO.

Puga, D. (2001) Un lugar en el sol. Inmigración internacional de jubilados hacia Costa Rica. En Rosero (Coord.). Población del istmo 2000: familia, migración, violencia y medio ambiente, 253-276. San José: Centro Centroamericano de población.

Pujol, R., Pérez, E. \& Sánchez, L. (2009). Hacia un cambio en la oferta de vivienda en la GAM: una exploración desde los grandes desafíos planteados por la demanda potencial de vivienda de la región. En CONARE (2000). Decimoquinto Informe Estado de la Nación en Desarrollo Humano Sostenible. San José, Costa Rica: CONARE, Defensoría de los Habitantes, PNUD

Quirós Castro, R. (2007). "Las representaciones sociales de la clase media en las coyunturas de conflicto social en la Costa Rica neoliberal, 1984 - 2000". Diálogos Revista Electrónica de Historia, 8 (1). Recuperado de http://revistas.ucr.ac.cr/ index.php/dialogos/article/view/6164

Quirós, L. (2013, Mayo). "Desarrollos mixtos y miniciudades”. Especial Bienes Raíces. Revista Summa, 110-111.

Revista Summa (2011, Mayo). "Banca da oxígeno a construcción”. Especial Bienes Raíces. Revista Summa, 84-86.

Revista Summa (2012, Mayo). "Ciudades en Movimiento" Especial Bienes Raíces. Revista Summa, 86-96

Robinson, W.I. (1998) "(Mal)Development in Central America: Globalization and Social Change." Development and Change, 29, 467- 497.

Robles Rivera, F. (2010). "Nuevos espacios de acumulación: modelo de ajuste estructural en El Salvador y Costa Rica (1980-1999)." Revista de Ciencias Sociales 128/129, 97-117.

Robles Rivera, F. (2011). "Los de entonces ya no son los mismos. Acumulación por desposesión en la última década en El Salvador y Costa Rica. Anuario de Estudios Centroamericanos 37, 105-137. Universidad de Costa Rica.

Robles Rivera, F. (2012). "Los dueños de la palabra en Costa Rica en un contexto de reforma neoliberal". Revista Rupturas 1 (2), 144-161. San José.

Rojas, C. (2010). "Adaptaciones institucionales en la época neoliberal". Política y Cultura, 34, 131-157.

Saldomando, A. (2006). Aspectos económicos del neoliberalismo en Centro América, elementos para un debate. Centro Investigaciones de la Comunicación. Recuperado de http://cinco.org.ni/archive/16.pdf

Segovia, A. (2005) Integración real y grupos de poder económico en América Central: implicaciones para el desarrollo y de democracia en la región. San José: Fundación Friedrich Ebert.

Séguin, A.M. \& Negrón, P. P. (2006). La segregación socio-espacial urbana: Una mirada sobre Puebla, Puerto España, San José y San Salvador. San José, Costa Rica: FLACSO.

Smith, N. (2001). "Nuevo globalismo, nuevo urbanismo", Documents d'Anàlisi Geogràfica $38,15-32$

Smith, N. (2005). El redimensionamiento de las ciudades: la globalización y el urbanismo neoliberal. En D. Harvey, y N., Smith. (Eds.). Capital Financiero, Propiedad Inmobiliario y Cultura (pp. 59-78). Barcelona: Museu d'Art Contemporani de Barcelona.

Sojo, C. (1991). La utopía del Estado mínimo. Influencia de AID en Costa Rica en los años ochenta. Managua. CEPAS-CRIES. 
Sojo, C. (1992). La mano visible del mercado. La asistencia de Estados Unidos al sector privado costarricense en la década de los ochenta. Managua: CEPAS.CRIES.

Sojo, C. (1995). "En el nombre del padre: Patrimonialismo y democracia en Costa Rica". En: Malestar con la política, 59-94. San José, Costa Rica: FLACSO.

Solano, F. \& Madrigal, E. (2009). Informe Situación de la Vivienda y el Desarrollo Urbano en Costa Rica en el 2008. San José: Fundación Promotora de Vivienda (FUPROVI), Unidad de Investigación (UNIN).

Solano, F. \& Rojas, W. (2010). Informe Situación de la Vivienda y el Desarrollo Urbano en Costa Rica en el 2009. San José: Fundación Promotora de Vivienda (FUPROVI), Unidad de Investigación (UNIN).

Solano, F. \& Rojas, W. (2013). Informe Situación de la Vivienda y el Desarrollo Urbano en Costa Rica en el 2012. San José: Fundación Promotora de Vivienda (FUPROVI), Unidad de Investigación (UNIN).

Solano, F. \& Rojas, W. (2015). Informe Situación de la Vivienda y el Desarrollo Urbano en Costa Rica en el 2014. San José: Fundación Promotora de Vivienda (FUPROVI), Unidad de Investigación (UNIN).

The Guardian. (2013, Septiembre). "Guatemalan capital's wealthy offered haven in gated city". Reuperado de: https://www.theguardian.com/world/2013/jan/09/ guatemalan-capital-wealthy-haven-city

Thuillier, G. (2005). "El impacto socio-espacial de las urbanizaciones cerradas: el caso de la Región Metropolitana de Buenos Aires." Revista Latinoamericana de Estudios Urbano Regionales Eure, 31 (93): 5-20. Chile: Pontificia Universidad Católica de Chile.

UMPEG. (2015). Reporte de Ejecución POA de la Unidad Municipal de Planificación y Evaluación de la Gestión (UMPEG). Recuperado de Alcaldia Municipal del Distrito Central de Tegucigalpa. http://www.amdc.hn/PortalTransparencia/Documentos/ Planes/2015/Ejecucion-Presu/Enero-2015.pdf

Vega, M. (1984). "CODESA: política institucional y luchas por el poder (1974 - 1984)". Revista Centroamericana de Administración Pública, 7, 69-95.

Wallace, A. (2017, Noviembre 23) "Qué son las ZEDE, los polémicos territorios con los que Honduras quiere convertirse en el Hong Kong de América Latina que marcan las elecciones en el país centroamericano". BBC News. Recuperado de https:// www.bbc.com/mundo/noticias-america-latina-42030850 